\title{
Therapeutic targets for HIV-I infection in the host proteome
} Winnie S Liang ${ }^{\dagger 2}$, Anil Maddukuri ${ }^{\dagger 1}$, Tanya M Teslovich ${ }^{3}$, Cynthia de la Fuente $^{1}$, Emmanuel Agbottah ${ }^{1}$, Shabnam Dadgar1, Kylene Kehn ${ }^{1}$, Sampsa Hautaniemi ${ }^{4}$, Anne Pumfery ${ }^{1}$, Dietrich A Stephan ${ }^{* 2}$ and Fatah Kashanchi*1,5

\author{
Address: ${ }^{1}$ Department of Biochemistry and Molecular Biology, George Washington University School of Medicine, Washington, DC 20037, USA, \\ ${ }^{2}$ Neurogenomics Division, Translational Genomics Research Institute, Phoenix, AZ 85004, USA, ${ }^{3}$ Institute for Genetic Medicine, Johns Hopkins \\ Medical School, Baltimore, MD 21205, USA, 4 Institute of Signal Processing, Tampere University of Technology, PO Box 553, 33101, Tampere, \\ Finland and ${ }^{5}$ The Institute for Genomic Research, TIGR, Rockville, MD 20850, USA \\ Email: Winnie S Liang - wliang@tgen.org; Anil Maddukuri - anilm@gwu.edu; Tanya M Teslovich - tanya@jhmi.edu; Cynthia de la \\ Fuente - bcmclf@gwumc.edu; Emmanuel Agbottah - bcmeta@gwumc.edu; Shabnam Dadgar - sdadgar@gwu.edu; \\ Kylene Kehn - bcmkwk@gwumc.edu; Sampsa Hautaniemi - sampsa@mit.edu; Anne Pumfery - bcmamp@gwumc.edu; \\ Dietrich A Stephan* - dstephan@tgen.org; Fatah Kashanchi* - bcmfxk@gwumc.edu \\ * Corresponding authors †Equal contributors
}

Published: 2I March 2005

Retrovirology 2005, 2:20 doi:10.1186/1742-4690-2-20

This article is available from: http://www.retrovirology.com/content/2/I/20

(C) 2005 Liang et al; licensee BioMed Central Ltd.

This is an Open Access article distributed under the terms of the Creative Commons Attribution License (http://creativecommons.org/licenses/by/2.0), which permits unrestricted use, distribution, and reproduction in any medium, provided the original work is properly cited.
Received: 10 February 2005

Accepted: 21 March 2005

\begin{abstract}
Background: Despite the success of HAART, patients often stop treatment due to the inception of side effects. Furthermore, viral resistance often develops, making one or more of the drugs ineffective. Identification of novel targets for therapy that may not develop resistance is sorely needed. Therefore, to identify cellular proteins that may be up-regulated in HIV infection and play a role in infection, we analyzed the effects of Tat on cellular gene expression during various phases of the cell cycle.
\end{abstract}

Results: SOM and k-means clustering analyses revealed a dramatic alteration in transcriptional activity at the GI/S checkpoint. Tat regulates the expression of a variety of gene ontologies, including DNA-binding proteins, receptors, and membrane proteins. Using siRNA to knock down expression of several gene targets, we show that an Octl/2 binding protein, an HIV Rev binding protein, cyclin A, and PPGB, a cathepsin that binds NA, are important for viral replication following induction from latency and de novo infection of PBMCs.

Conclusion: Based on exhaustive and stringent data analysis, we have compiled a list of gene products that may serve as potential therapeutic targets for the inhibition of HIV-I replication. Several genes have been established as important for HIV-I infection and replication, including Pou2AFI (OBF-I), complement factor $\mathrm{H}$ related 3, CD4 receptor, ICAM-I, NA, and cyclin AI. There were also several genes whose role in relation to HIV-I infection have not been established and may also be novel and efficacious therapeutic targets and thus necessitate further study. Importantly, targeting certain cellular protein kinases, receptors, membrane proteins, and/or cytokines/chemokines may result in adverse effects. If there is the presence of two or more proteins with similar functions, where only one protein is critical for HIV-I transcription, and thus, targeted, we may decrease the chance of developing treatments with negative side effects. 


\section{Background}

With the rapid emergence of the HIV-1 and AIDS pandemic, tremendous effort has been directed towards development of effective treatments and vaccines. Currently, HAART is the only therapeutic option available for seropositive and symptomatic individuals, and is comprised of targeted inhibitors of HIV-1 reverse transcriptase (NNRTIs and NRTIs) and/or protease (PI) and the newly FDA approved gp41-inhibitor Fuzeon/T20 [1]. Though HAART is effective in prolonging life, its use, coupled with other factors, engenders rapid development of multiple drug-resistant strains. Therefore, the comprehensive elucidation of HIV-1-mediated effects on host cellular networks is urgently needed for rational therapeutic targets. HIV-1 infection, pathogenesis, and AIDS development are largely due to the various retroviral structural, regulatory, and accessory proteins, but more importantly due to efficient 'hijacking' of cell regulatory machineries, including the differential expression of receptors, transcription, mRNA processing, and translation factors. While there has been much research on the effects of viral proteins on host cellular pathways, HIV-1 Tat appears to be the most critical for viral transcription and replication.

HIV-1 Tat is absolutely required for productive, high titer viral replication. Though its sequence and a number of its functions have been uncovered, there is still much to learn about its replication-driven and pathogenic mechanisms, including the identification and characterization of Tatregulated cellular genes. With the advent of microarray technologies, it is now possible to assay the entire human genome for the effects of a single gene product, viral infection, or drug treatment. Many laboratories have previously demonstrated the effects of Tat on cell cycleregulated transcription [2-4]. The finding that Tat activates gene expression at both the $\mathrm{G}_{1}$ (TAR-dependent) and $\mathrm{G}_{2}$ (TAR-independent) phases of the cell cycle demonstrates a concerted effort by Tat to take full advantage of cell cycle regulatory checkpoints. These findings prompted us to explore the effects of constitutive Tat expression on the expression profile of 1,200 host cellular genes in HIV-1 infected unsynchronized cells [5]. We observed that while the majority of cellular genes were down-regulated, especially those with intrinsic receptor tyrosine kinase activity, numerous $S$ phase and translation-associated genes were up-regulated. These findings and the fact that inducing a $\mathrm{G}_{1} / \mathrm{S}$ block on infected cells dramatically reduces viral transcription and progeny formation [6-8], prompted us to follow and elucidate the effects of Tat on the host transcriptional profile throughout the entire cell cycle.

Here, we report the HIV-1 Tat-mediated effects on the host expression profile relative to the cell cycle. We first performed microarray experiments in unsynchronized Tatexpressing cells compared to empty vector-transfected cells. We subsequently performed similar experiments in synchronized cells at the $G_{1} / S$ and $G_{2} / M$ phase boundaries. Cells were then collected at $0 \mathrm{~h}, 3 \mathrm{~h}, 6 \mathrm{~h}$, and $9 \mathrm{~h}$ postrelease per treatment corresponding to a specific cell cycle stage, and cytoplasmic RNA was isolated for microarray analysis. After microarray analysis using the Affymetrix U95Av2 gene chip, we found a wide variety of gene ontologies that were affected by Tat through cell cycle progression. We confirmed that Tat differentially regulates the expression of a variety of genes at different phases of the cell cycle, with an overall inhibition of the cellular transcription profile. Using siRNA technology to 'knockdown' protein expression, we screened several of these genes as possible therapeutic targets for inhibition of HIV1 replication. We generated a comprehensive list of Tatinduced genes at each cell cycle phase, particularly the $\mathrm{G}_{1}$ / $S$ phase transition, and expanded the list of Tat-regulated cellular proteins and potential therapeutic targets.

\section{Results and Discussion Microarray design and analysis}

To understand which cellular genes were affected by Tat, we analyzed the transcription profile of $\sim 12,000$ gene transcripts using the Affymetrix U95Av2 gene chip. Cells were either transfected with the eTat plasmid or a pCep4 control vector. We chose to perform experimental and control conditions in duplicate to account for inter-chip variability. Figure 1A illustrates the cross-validity of the duplicate synchronized cell cycle experiments run for the eTat samples. The scatter plot graph logarithmically plots the probe set signal intensity values from the first experiment against those from the second experiment (average $\mathrm{R}^{2}$ value $=0.912$ ). Yellow spots represent gene probes with absent or marginal calls and the blue spots correspond to probes with present and marginal calls. Blue spots show less correlation and the yellow spots indicate the lowest level of correlation. Red spots represent those probes that displayed present calls in both experiments and thus demonstrate the highest level of correlation. The fold change lines indicate two-fold, three-fold, and ten-fold changes. Figure 1A shows the correlation of signal and detection values between the two experiments for each probe set, as well as the reliability of one dataset compared to its replicate. Similar results were observed for this analysis between the duplicate control pCep4 samples (data not shown). Though previous microarray experiments performed by us and others have used total nuclear and cytoplasmic RNA, we chose to isolate only cytoplasmic RNA because nuclear RNA would include RNAs that have been improperly spliced, or uncapped, and may have contain inappropriate poly-A tails, while cytoplasmic RNAs would yield almost a complete RNA population that has been properly processed prior to nuclear export and translation. As seen in Figure 1B, the RNA samples for both 
A)

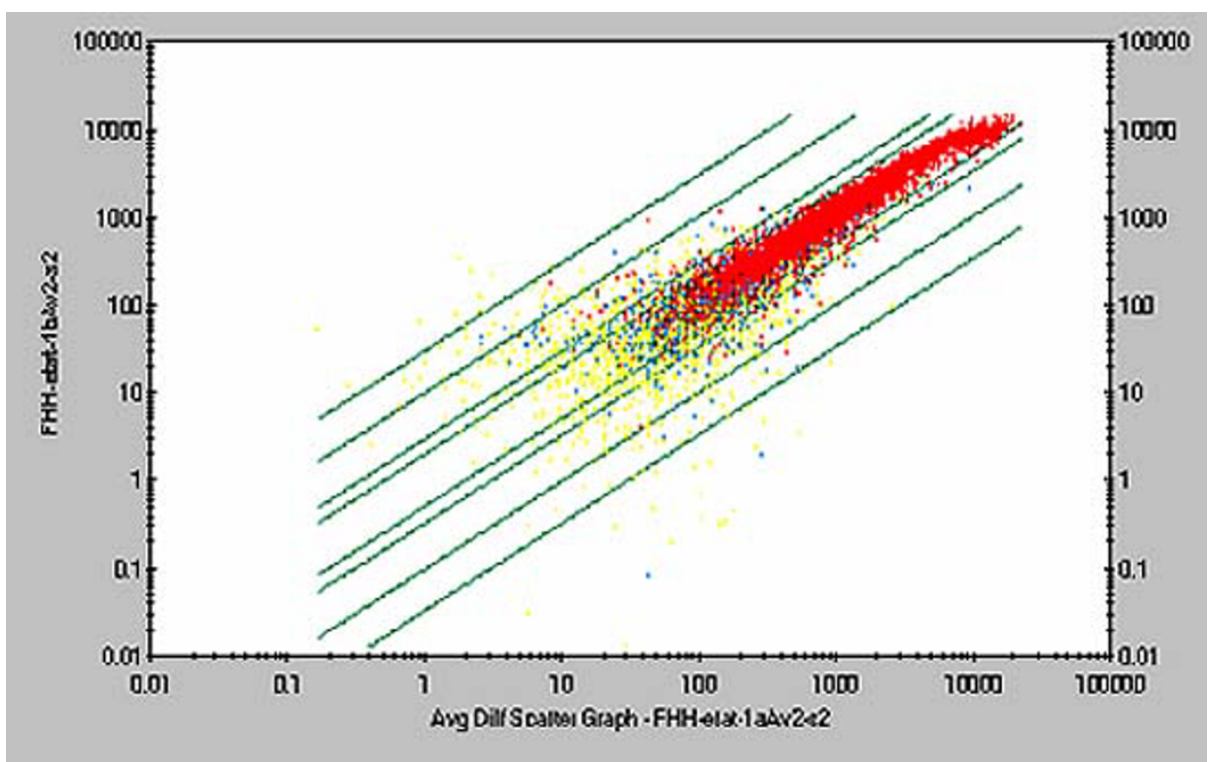

B)
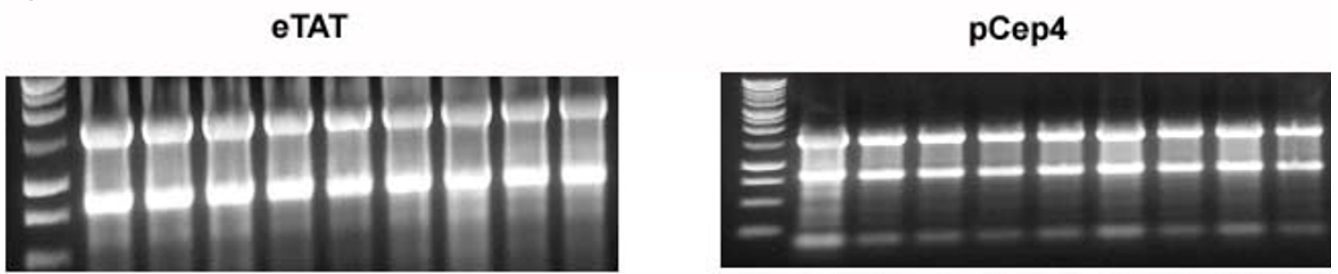

$\begin{array}{llllllllll}1 & 2 & 3 & 4 & 5 & 6 & 7 & 8 & 9 & 10\end{array}$

$\begin{array}{llllllllll}1 & 2 & 3 & 4 & 5 & 6 & 7 & 8 & 9 & 10\end{array}$

C)

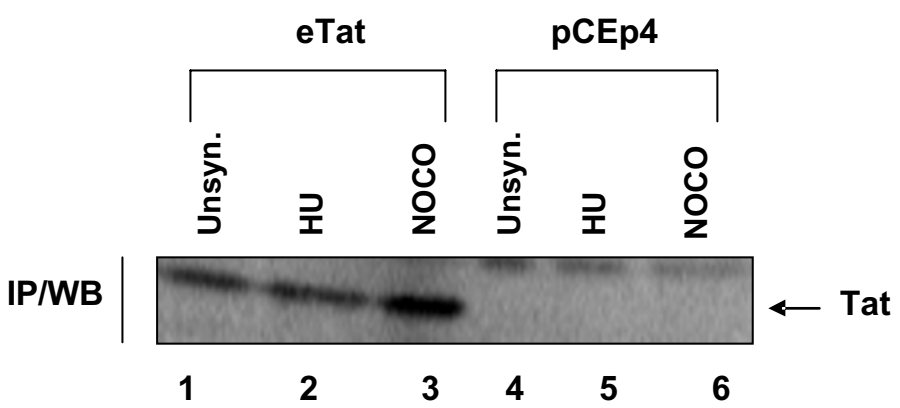

Figure I

Cross-validity of Tat samples and RNA isolation. (A) Cross-validity of the duplicate Tat samples analyzed. With a total of 32 gene chips, we analyzed the reliability of the gene chip samples relative to their respective replicate. The scatter graph logarithmically plots the signal intensity values of probe sets for one sample against those for a sample replicate. Each graph point indicates a common probe set between the two data sets and the value is determined by the intersection of the $x$ and $y$ values for that probe set. 2-fold, 3-fold, and 10 -fold change lines are defined by the following equations: $y=2 x$ and $y=1 / 2 x, y$ $=3 x$ and $y=1 / 3 x, y=10 x$ and $y=1 / 10 x, y=30 x$ and $y=1 / 30 x$. Yellow spots represent probes with absent-absent, absentmarginal, marginal-absent, and marginal-marginal detection calls on sample replicates. Blue spots represent those with absentpresent, present-absent, marginal-present, and present-marginal calls, while red spots represent probe sets with presentpresent detection calls. (B) Cytoplasmic RNA was isolated from all experimental and corresponding control samples, and quantitated by UV spectrophotometric analysis; $3 \mu \mathrm{g}$ was run on a I\% agarose gel for visual inspection. (C) IP/Westerns for Tat protein. Lanes I-3 are from eTat extracts and Lanes 4-6 are from control pCep4 cells; unsynchronized cells are shown in Lanes I and 4. 
experiments show good RNA integrity with defined $18 \mathrm{~S}$ and $28 \mathrm{~S}$ bands.

We first studied the effects of constitutive Tat expression on the host cell transcription profile in unsynchronized cells and then relative to the cell cycle phases. Initially, a heterogenous cell population of Tat-expressing cells was compared to one expressing the pCep4 vector to create a global Tat-induced transcription profile. In the latter experiment, samples were treated with either hydroxyurea (Hu) or nocodazole (Noco) for $18 \mathrm{~h}$ to obtain either a $\mathrm{G}_{1} /$ $\mathrm{S}$ or $\mathrm{G}_{2} / \mathrm{M}$ block, respectively. Cells blocked with Hu were $60 \%$ at $\mathrm{G}_{1}, 35 \%$ at $\mathrm{S}$, and $5 \%$ at the $\mathrm{G}_{2} / \mathrm{M}$ phase, while cells blocked with Noco were $6 \%$ at $\mathrm{G}_{1}, 24 \%$ at $\mathrm{S}$, and $70 \%$ at the $G_{2} / M$ phase (data not shown). Following cell cycle arrest, cells were washed and released in complete media. The $0 \mathrm{~h}$ time point following Hu treatment is representative of the $G_{1} / S$ phase of the cell cycle, while the 3 $\mathrm{h}, 6 \mathrm{~h}$, and $9 \mathrm{~h}$ time points correspond to the early $\mathrm{S}$, late $S$, and $G_{2}$ phases, respectively. Noco, a $G_{2} / M$ phase blocker, was added to the cell populations and the cells were likewise released. Samples were taken at the $0 \mathrm{~h}, 3 \mathrm{~h}$, $6 \mathrm{~h}$, and $9 \mathrm{~h}$ time points to obtain cells in the $\mathrm{M}$ and early, middle, and late $\mathrm{G}_{1}$ phases, respectively. Immunoprecipitation and western blot analysis of tat protein were also carried out to verify the presence of tat in the unsynchronized and synchronized Tat-expressing cells and those expressing the pCep4 vector (Figure 1C). Thus, we obtained and analyzed the HIV-1 Tat-induced transcription profile at every cell cycle stage. All cell cycle phase populations were confirmed using FACS analysis as previously shown [2].

\section{Gene expression analysis in unsynchronized Tat- expressing cells}

We analyzed the differential gene expression of a Tatexpressing cell population relative to that of a control population. This microarray analysis consisted of looking at $\sim 12,000$ genes in unsynchronized cells to ascertain the global effect of HIV-1 Tat-mediated transcriptional regulation on the host cell genome. Overall, we observed Tatinduced/-repressed differential expression of 649 genes ( $\sim 5 \%$ of genes screened) belonging to a wide variety of gene ontologies (Figure 2A). Figure 2B depicts gene ontologies for genes showing increased/decreased expression between the eTat and pCep4 samples. A few genes were represented as belonging to a variety of classifications and were placed into multiple categories. We observed the greatest effect ( $3 \%$ ) of Tat on genes encoding for cellular enzymes; secretory, metabolic, and apoptotic pathways; and RNA binding, DNA binding, cytoskeletal, protein synthesis, and receptor proteins, while the other gene ontologies were less affected by Tat expression. We also observed that $\sim 60 \%$ of the Tat affected genes were downregulated. These findings are consistent with the previ- ously published results by us and other laboratories $[5,9,10]$.

\section{HIV-I Tat-induced transcription profile}

Using a two-fold threshold to constrain our gene lists to those genes only significantly induced by Tat, we observed many genes that were expressed during all cell cycle phases, with fewer genes that were exclusive to only one cell cycle phase. This can be seen in both the self-organizing maps (SOMs) and k-means analysis graphs [Figures 4 and 3, respectively \& Additional Files 5, 6, and 7]. In the 3 sets of SOMs generated using three separate filtering rules, we observed many genes that were relatively consistent in their expression patterns through most cell cycle phases. This was also evident in the k-means graphs that contain gene clusters whose expression was relatively linear [see Additional File 7: sets 1, 10, 11, and 14]. In the k-means analysis, the $y$-axis represents the normalized intensity values for the genes analyzed and the x-axis contains two sets of eight time points for each condition. K-means clustering allows for the elucidation of those genes with similar temporal expression profiles. As shown in [Additional File 7], the various graphs correspond to separate clusters of genes whose expression is similar in Tat-expressing cells relative to cell cycle progression.

Based on the k-means clustering methods, we observed a coordinated up-regulation of 228 genes during the $G_{1} / S$ phase transition in set 14 (Figure $3 \mathrm{~B}$ ) and 54 genes in set 12 (Figure 3A). On the other hand, set 5 (Figure 3C) displays genes whose expression peaks at different time points in the cell cycle, but are specifically down-regulated at the $G_{1} / S$ boundary. Set 12 (Figure $3 A$ ) was very similar to the results seen with the $\mathrm{G}_{1} / \mathrm{S}$ SOM (Figure 4 ), in which genes were up-regulated at the $G_{1} / S$ phase and continued to be highly expressed until the $G_{2}$ phase. Set 12 illustrates the increased expression of various cathepsins $(\mathrm{L}, \mathrm{L} 2, \mathrm{Z}$, PPGB), receptors (EGFR, lamin $B$, poliovirus), solute/ion carrier transporters, and MHC molecules (HLA-C, HLA-A, GRP58).

In set 14 (Figure 3B), genes whose expression peaked at the $G_{1} / S$ phase transition were observed, though a greater number of genes relative to set 12 with similar expression patterns and functions were found. For example, we observed up-regulation of apoptosis regulators (UDPgalactose ceramide glucosyltransferase, BAX, BAX inhibitor 1, TRAIL receptor 2, thioredoxin peroxidase, CD47, API5-like 1), receptors/adhesion proteins (CCRL2, LIFR, EGFR, FGFR1, syndecan 4, syndecan 1, IL-4R, IL-13R, lymphotoxin B receptor), signaling mediators (Grb2, AKAP1, IRAK1, CaM-kinase II, calcineurin), and proteins involved in transcriptional regulation (BAF60C, NFI/C, ATF6). Interestingly, 26 genes in this cluster were related to the ER-Golgi protein transport pathway, suggesting a 
A)

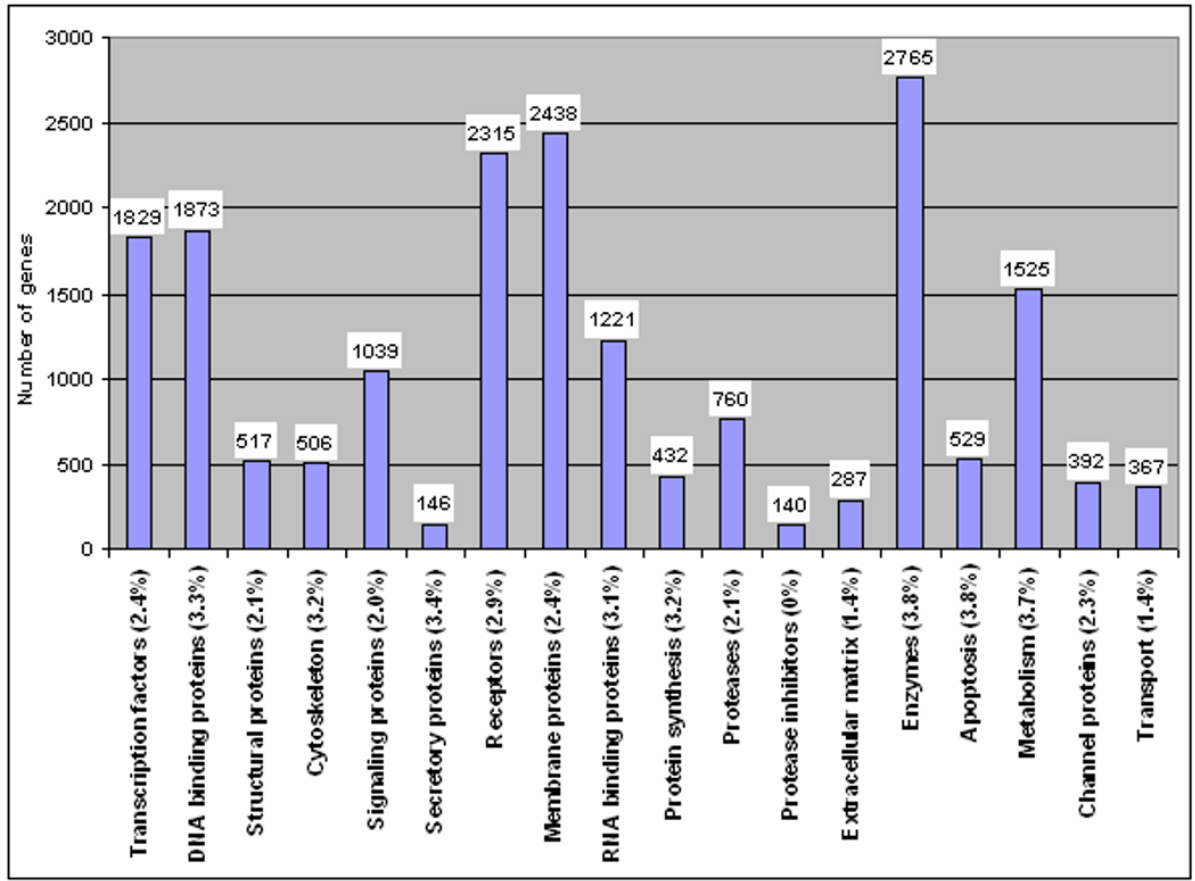

B)

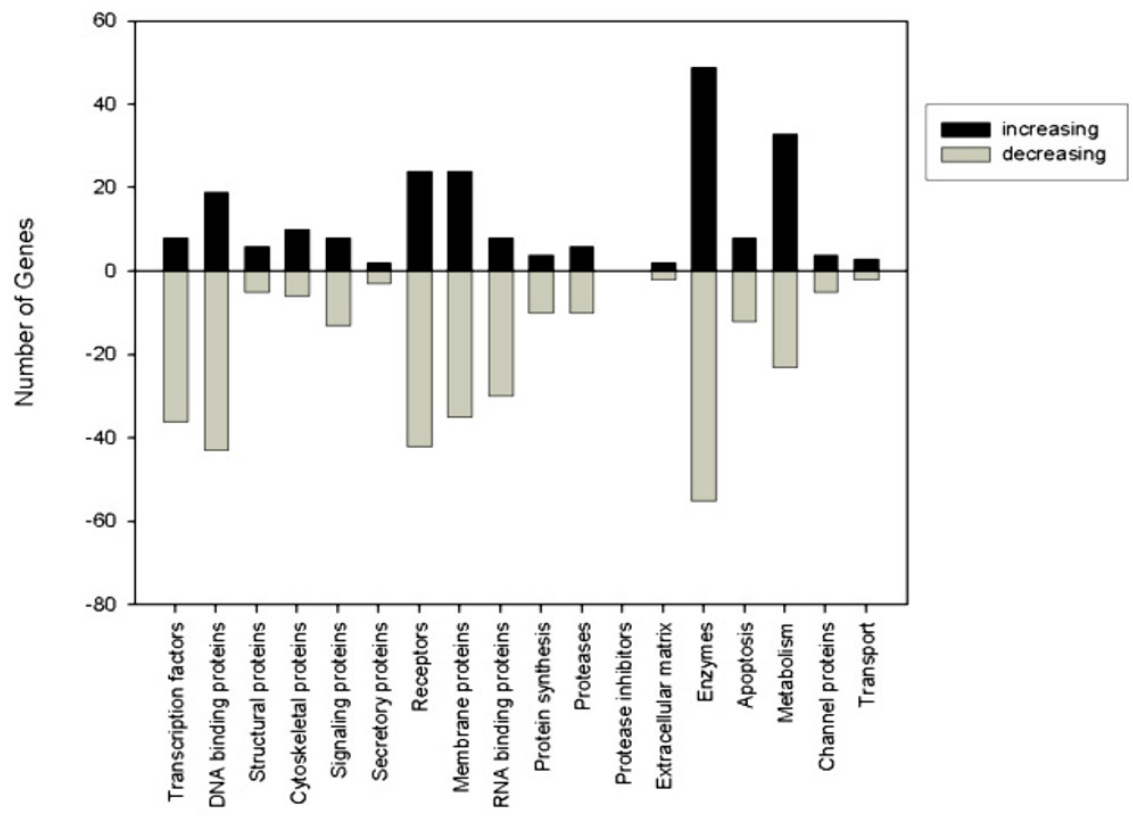

Figure 2

Gene ontologies present on the human U95Av2 chip and those specifically induced by Tat. (A) The U95Av2 gene chip was surveyed to determine the ontology of genes represented on the chip, as well as the corresponding number of genes belonging to each category. The percentages next to each classification correspond to the percentage of genes affected by Tat. (B) HIV-I Tat-induced/repressed genes in an unsynchronized HeLa-eTat cell population. The number of genes induced/ repressed by Tat, as well as the various classifications, is shown. 

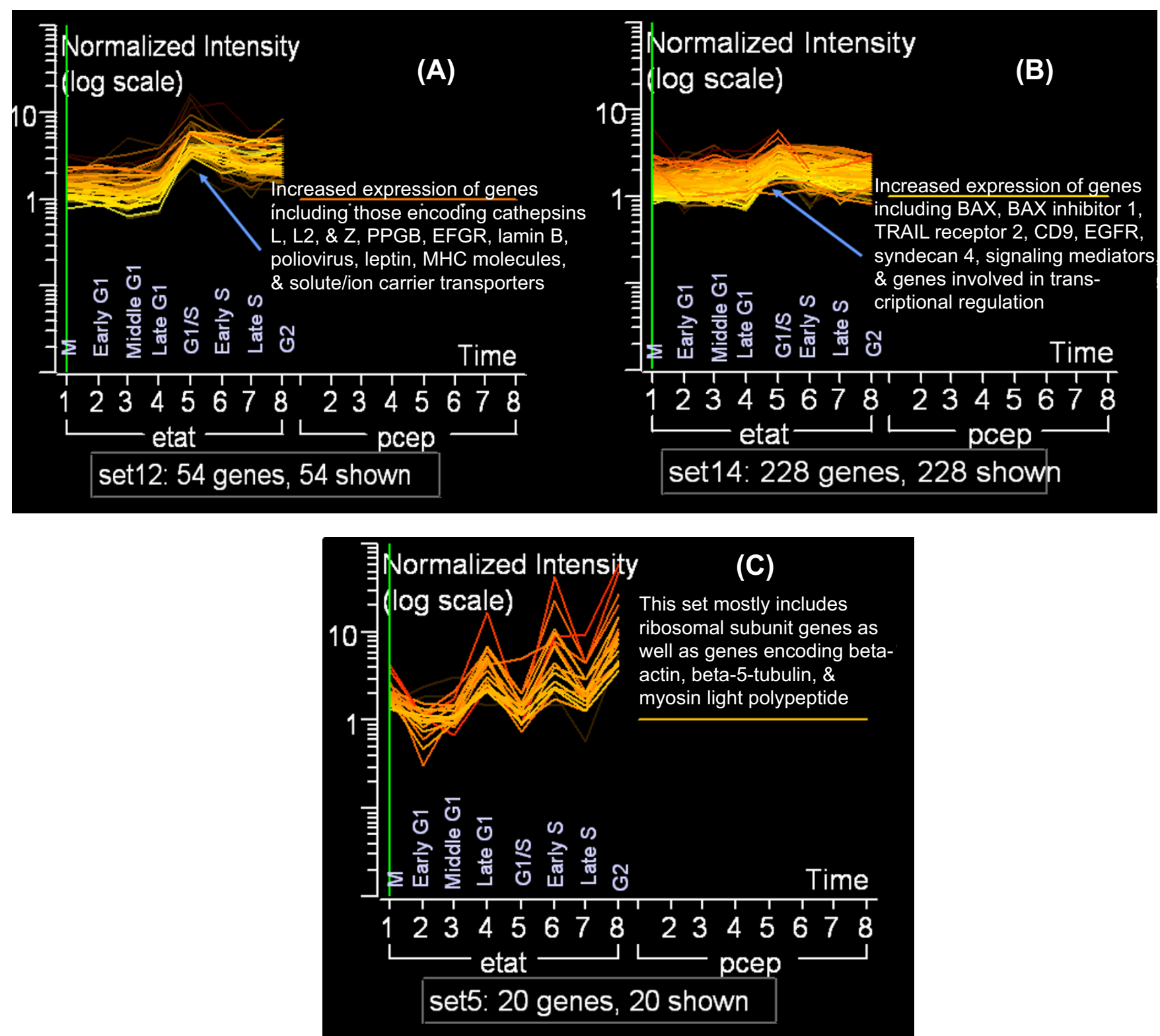

\section{Figure 3}

K-Means clustering analysis of Tat-induced genes. The temporal differential gene expression in Tat cells was compared to respective control samples and analyzed using the k-means clustering algorithm. The coordinated expression profiles are representative of the 32 chips analyzed (16 eTat and 16 pCep4). The y-axis represents the log scale of the normalized intensity of the genes shown (data was normalized against the corresponding control samples). The $x$-axis corresponds to the various cell cycle phases: I) $M$ phase, 2) early $G_{1}, 3$ ) middle $G_{1}, 4$ ) late $G_{1}, 5$ ) $G_{1} / S, 6$ ) early $S, 7$ ) late $S$, and 8) $G_{2}$. Fifteen clusters were found based on the parameters used [see Additional File 7] and three are shown in 3A-C. Figure 3A shows altered genes at the GI/S for cathepsins, and various cellular receptors, while Figure 3B shows a close-up of apoptotic regulated genes, signal transduction and transcription factors. Figure $3 \mathrm{C}$ shows genes that dramatically oscillate at every stages of cell cycle in Tat expressing cells, including ribosome and actin/cytoskeleton genes.

dependence on efficient protein processing and intracellular transport. These findings suggest an increase in Tatinduced receptor-mediated signaling and transcription, and most importantly, the increased expression of membrane proteins and antigens involved in promoting HIV-1 replication and immune evasion. 
U-matrix
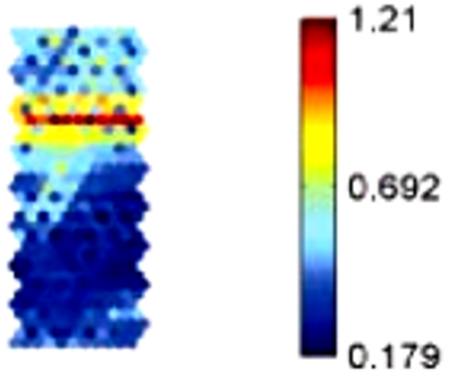

mid G1 phase

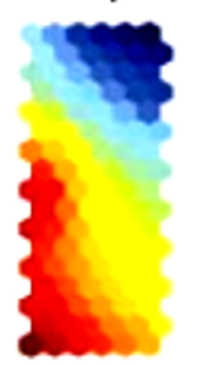

early S phase

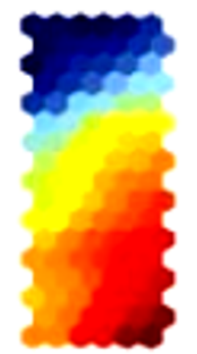

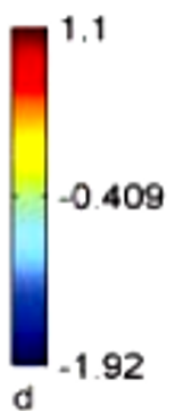

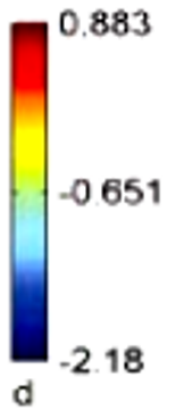

$M$ phase

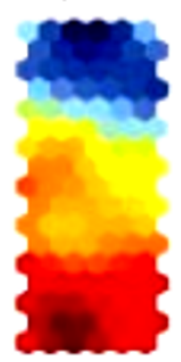

late $\mathrm{G} 1$ phase

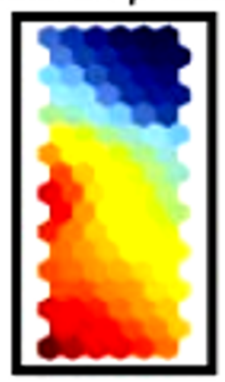

late S phase

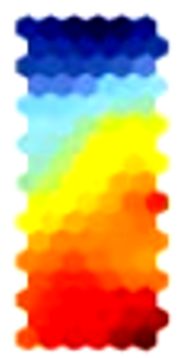

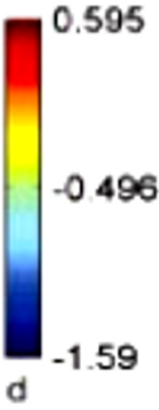

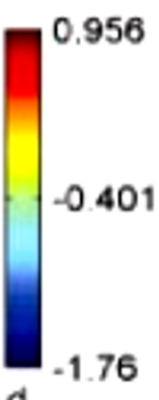

d

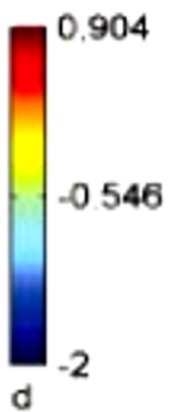

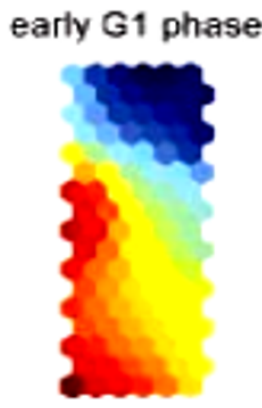
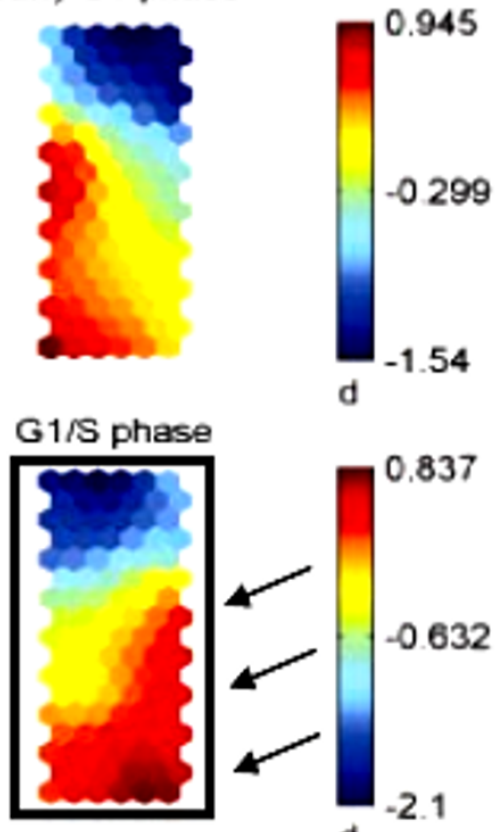

0.837
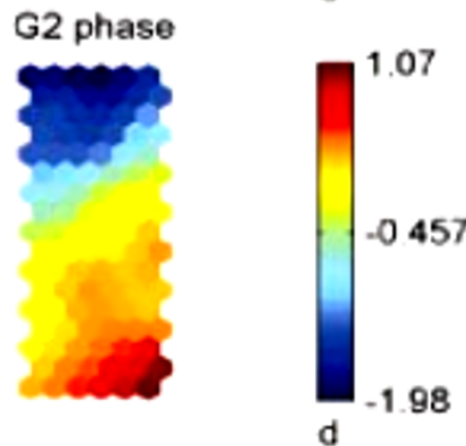

Figure 4

Temporal SOM analysis of HIV-I Tat-induced cellular genes in synchronized Tat cells. 3 separate filters were applied to remove genes that did not display at least a I.5, 2, or 3-fold change at each time point analyzed in the 16 eTat chips (see Methods); each filter produced a discrete dataset that was applied to SOM analysis. The third and most restrictive dataset is shown here. Genes that were significantly up (red) and down-regulated (blue) are shown. The U-matrix identifies which genes are similar to each other in terms of expression profile (blue) separated by a "boundary" (red). This SOM graph contains 17 rows and 6 columns of neurons, represented as coordinates. The arrows adjacent to the $G_{1} / S$ SOM indicate those genes significantly up-regulated during this transition and $S$ phase, and those that show decreased expression in the $G_{1}$ phase.

On the other hand, set 5 (Figure 3C) shows 20 genes whose expressions peaked at late $G_{1}$, early $S$, and then again at $G_{2}$, while their expressions were lowest at early $G_{1}$. This set contains primarily ribosomal subunit genes. We previously observed very similar results in our microarray experiment using Tat-expressing H9 cells [5], where we saw a significant up-regulation of numerous ribosomal subunit genes and translation initiation factors. The dramatic temporal expression of the ribosomal subunits for the $40 \mathrm{~S}$ and $60 \mathrm{~S}$ components in early S, as seen in set 5 , may be indicative of a critical coupling of transcription and translation for efficient viral RNA production.

\section{Tat-mediated gene expression during $G_{I} / S$ phase}

Using a complementary technique for unsupervised clustering, we looked at those genes that were induced by HIV-1 Tat during the late $G_{1}$ phase and the $G_{1} / S$ phase transition since our previous findings indicated that these cell cycle phases were starting points for transcription of the HIV-1 long terminal repeat (LTR) and activated viral 
Table I: SOM and K-means Analysis of Tat-upregulated genes at the $G_{I} / S_{\text {phase. }}{ }^{a}$

\begin{tabular}{|c|c|c|c|c|}
\hline Gene Ontology & Accession \# & Gene Title & Gene Symbol & Unigene ID \\
\hline Transcription/ & D83782 & SREBP cleavage-activating protein & SCAP & Hs.437096 \\
\hline DNA binding & AC004770 & fatty acid desaturase 3 & FADS3 & Hs.21765 \\
\hline \multirow[t]{13}{*}{ Enzymes } & Y08685 & serine palmitoyltransferase, long chain base subunit I & SPTLCI & Hs.90458 \\
\hline & D50840 & UDP-glucose ceramide glucosyltransferase & UGCG & Hs. 432605 \\
\hline & AF03896I & mannose-P-dolichol utilization defect I & MPDUI & Hs.95582 \\
\hline & U67368 & exostoses (multiple) 2 & EXT2 & Hs.75334 \\
\hline & M22488 & bone morphogenetic protein I & BMPI & Hs. I 274 \\
\hline & AF002668 & degenerative spermatocyte homolog, lipid desaturase (Drosophila) & DEGS & Hs.299878 \\
\hline & $\mathrm{AB} 016247$ & sterol-C5-desaturase-like & SC5DL & Hs.287749 \\
\hline & $X 15525$ & acid phosphatase 2, lysosomal & ACP2 & Hs.75589 \\
\hline & DI3643 & 24-dehydrocholesterol reductase & DHCR24 & Hs.756I6 \\
\hline & AF020543 & palmitoyl-protein thioesterase 2 & PPT2 & Hs.332138 \\
\hline & AL050II8 & fatty acid desaturase 2 & FADS2 & Hs.388I64 \\
\hline & MI6424 & beta-hexosaminidase A (alpha polypeptide) & HEXA & Hs.4III57 \\
\hline & LI3972 & sialyltransferase 4A (beta-galactoside alpha-2,3-sialyltransferase) & SIAT4A & Hs.356036 \\
\hline Membrane/ & D79206 & syndecan 4 (amphiglycan, ryudocan) & SDC4 & Hs.252189 \\
\hline \multirow[t]{7}{*}{ Antigens } & M90683 & HLA-G histocompatibility antigen, class I, G & HLA-G & Hs.5I 2152 \\
\hline & $\times 58536$ & major histocompatibility complex, class I, C \& B & HLA-C, B & Hs.7796I \\
\hline & AF068227 & ceroid-lipofuscinosis, neuronal 5 & CLN5 & Hs.302I3 \\
\hline & U725।5 & putative protein similar to nessy (Drosophila) & $\mathrm{C} 3 \mathrm{~F}$ & Hs.530552 \\
\hline & $X 85116$ & stomatin & STOM & Hs.439776 \\
\hline & Z26317 & desmoglein 2 & DSG2 & Hs. 412597 \\
\hline & $\mathbf{S 9 0 4 6 9}$ & P450 (cytochrome) oxidoreductase & POR & Hs.354056 \\
\hline \multirow{8}{*}{$\begin{array}{l}\text { Receptors/ } \\
\text { Ligands }\end{array}$} & U97519 & podocalyxin-like & PODXL & Hs. 16426 \\
\hline & $\mathrm{A} / 263885$ & interleukin 27 receptor, alpha & IL27RA & Hs. I3278I \\
\hline & U60805 & oncostatin $M$ receptor & OSMR & Hs.238648 \\
\hline & M63959 & low density lipoprotein receptor-related protein associated protein I & LRPAPI & Hs.75।40 \\
\hline & L2593। & lamin B receptor & LBR & Hs.435I66 \\
\hline & $\times 00588$ & epidermal growth factor receptor & EGFR & Hs.77432 \\
\hline & M259I5 & clusterin & CLU & Hs.436657 \\
\hline & X87949 & heat shock $70 \mathrm{kDa}$ protein 5 (glucose-regulated protein, $78 \mathrm{kDa}$ ) & HSPA5 & Hs.310769 \\
\hline \multirow[t]{3}{*}{ Proteases } & AF032906 & cathepsin Z & CTSZ & Hs.252549 \\
\hline & AB001928 & cathepsin L2 & CTSL2 & Hs.874I7 \\
\hline & Y00264 & Amyloid beta (A4) precursor protein & APP & Hs. 177486 \\
\hline \multirow{9}{*}{$\begin{array}{l}\text { Protein } \\
\text { transport/ } \\
\text { Chaperone }\end{array}$} & D83I74 & serine (or cysteine) proteinase inhibitor, clade $\mathrm{H}$, member I & SERPINHI & Hs.24I579 \\
\hline & Z49835 & glucose regulated protein, 58 kDa & GRP58 & Hs.II 0029 \\
\hline & X97335 & A kinase (PRKA) anchor protein I & AKAPI & Hs.78921 \\
\hline & X90872 & gP25L2 protein & HSGP25L2G & Hs.279929 \\
\hline & D49489 & thioredoxin domain containing 7 (protein disulfide isomerase) & TXNDC7 & $\mathrm{Hs.212102}$ \\
\hline & AF0I3759 & calumenin & CALU & Hs.7753 \\
\hline & AL008726 & protective protein for beta-galactosidase (galactosialidosis) & PPGB & Hs. II8126 \\
\hline & Z50022 & pituitary tumor-transforming I interacting protein & PTTGIIP & Hs.369026 \\
\hline & AA487755 & FK506 binding protein 9, $63 \mathrm{kDa}$ & FKBP9 & Hs.497972 \\
\hline \multirow{3}{*}{$\begin{array}{l}\text { lon channel/ } \\
\text { transporter }\end{array}$} & U81800 & solute carrier family 16, member 3 & SLCI6A3 & Hs.386678 \\
\hline & $M 23114$ & ATPase, $\mathrm{Ca}++$ transporting, cardiac muscle, slow twitch 2 & ATP2A2 & Hs.374535 \\
\hline & j04027 & ATPase, $\mathrm{Ca}++$ transporting, plasma membrane I & ATP2B I & Hs.20952 \\
\hline
\end{tabular}


Table I: SOM and K-means Analysis of Tat-upregulated genes at the $G_{I} / S$ phase. ${ }^{a}$ (Continued)

\begin{tabular}{lllll}
\hline & AL049929 & ATPase, H+ transporting, lysosomal accessory protein 2 & ATP6AP2 & Hs. 183434 \\
& AL096737 & solute carrier family 5, member 6 & SLC5A6 & Hs.43735 \\
\hline \multirow{2}{*}{ Unknown/Other } & AF052159 & protein tyrosine phosphatase-like, member b & PTPLB \\
& DI4658 & KIAA0102 gene product & KIAA0102 & Hs.87095 \\
& Al867349 & nicastrin-like protein & NICALIN & Hs.24983 \\
& AL031228 & solute carrier family 39 (zinc transporter), member 7 & SLC39A7 & Hs.66776 \\
& X57398 & nodal modulator I, 2, 3 & NOMOI, 2, 3 Hs.429975
\end{tabular}

a Bolded genes indicate those genes upregulated at the GI/S transition (found using both SOM and k-means analyses)

transcription [2]. The SOM analysis makes it easier to visualize the dramatic cell cycle effects of Tat on the total gene dataset. In this analysis, red areas indicate up-regulated genes, while blue indicates down-regulated genes, and yellow represents minor effects on gene expression. The U-matrix allows visualization of those clusters in the SOM that show significant expression changes. Each hexagon or neuron corresponds to a group of genes with similar expression patterns. We performed 3 filters to generate SOMs, with the last filter being the most restrictive (Figure 4 ). The most restrictive list includes genes that show a 3fold increase or decrease in expression between the experimental and control samples at each time point. For this particular SOM, genes were removed if their average signal ratio fell between 0.333 and 3.0 across all time points tested and displayed absent calls at any time point.

Using the SOM analysis from the third filter (Figure 4), we observed a similar transcription profile throughout the $\mathrm{G}_{1}$ phase, with a marked difference at the $G_{1} / S$ transition. This is seen with the dramatic induction of those genes represented in the red and dark red neurons at the bottom right portion of the $\mathrm{G}_{1} / \mathrm{S}$ SOM. Repression of genes on the left side of the $G_{1}$ component plane, when cells enter the $\mathrm{G}_{1} / \mathrm{S}$ transition, was also observed. Interestingly, the $\mathrm{G}_{1} / \mathrm{S}$ profile remained relatively constant through the $S$ phase, while upon entering $G_{2}$, there was an overall reduction in Tat-mediated gene activation. This can be seen with the greater percentage of blue neurons at the $\mathrm{G}_{2}$ phase concomitant with a reduction of dark red neurons. We generated a list of genes up-regulated at the $G_{1} / S$ transition that were seen in both k-means and SOM clustering analyses (Table 1). Bolded genes are those that have already been shown to be involved in HIV-1 infection. It is important to note that there were a significant number of genes that were identified as similarly dysregulated by using both the k-means and SOM analyses across all time points.

Numerous signaling receptors were shown to be up-regulated upon Tat expression. The oncostatin $M$ receptor is normally bound by the IL- 6 cytokine family member and is increased in HIV-1 infection [11]. Interestingly, oncos- tatin $\mathrm{M}$ has been shown to stimulate the production of immature and mature T cells in the lymph nodes of transgenic mice [12]. It has also been shown that cdk9, a component of pTEFb, can also bind gp130, which is a common subunit recognized by the IL- 6 cytokine family [13]. Expression of the 4-1BBL cytokine, a T-cell co-stimulatory molecule (i.e. induces IL-2 production and T-cell proliferation) that is involved in the antigen presentation process and generation of a CTL response was also increased $[14,15]$.

Similarly, we observed the up-regulation of LFA-3, ICAM1 , and other membrane proteins and receptors. These membrane proteins serve as additional activation signals and molecules involved in the transmission of free virus to bystander, uninfected cells [16-18]. Interestingly, a recent report illustrates the ability of soluble ICAM (sICAM) to promote infection of resting cells and cell cycle progression after initiating $\mathrm{B}$ and $\mathrm{T}$ cell interactions [19]. Syndecan 4 was also up-regulated by Tat at the $G_{1} / S$ phase. Syndecans are a type of heparan sulfate proteoglycan (HSPG) that is able to efficiently attach to HIV-1 virions, protect them from the extracellular environment, and efficiently transmit the captured virions to permissive cells [20]. We also observed the up-regulation of the CXCR4 co-receptor that is critical for infection by X4 HIV-1 strains. Likewise, the SDF receptor 1 had increased expression. SDF-1 is the ligand for the CXCR4 co-receptor and can block HIV-1 infection via co-receptor binding. Therefore, the expression of the SDF receptor 1 could serve as an alternate binding site for SDF-1, allowing CXCR4 to be available for HIV-1 gp120/gp41-binding. Fractalkine, the ligand for the CX3CR1 receptor, has been shown to be important in the adhesion, chemoattraction, and activation of leukocytes [21], was also up-regulated by Tat expression. Overall, these proteins serve to increase the efficiency of HIV-1 infection, transmission to other cells, activation of T cells, and the recruitment of circulating leukocytes to infection sites.

A critical feature of HIV-1 infection is its ability to evade host immune responses and subsequently create a state of 
Table 2: Tat-upregulated genes not induced in other genetic diseases profiled.

\begin{tabular}{|c|c|c|}
\hline Accession \# & Fold Change & Gene Name \\
\hline DI3243 & 1.9 & Pyruvate kinase $\mathrm{L}$ \\
\hline Z49194 & 4.1 & Pou2AFI (OBF-I) \\
\hline AF072099 & 3.1 & LILRB4 \\
\hline U61836 & 0.2 & SMOX \\
\hline J00117 & 10.8 & CGB \\
\hline$\times 02612$ & 2.2 & Cytochrome P(I)-450 (CYPIAI) \\
\hline YI285I & 0.8 & P2X7 receptor \\
\hline Al349593 & 0.6 & Similar to hemoglobin epsilon chain \\
\hline AF055007 & 3.9 & MARCH-III \\
\hline AB002449 & 3.9 & Hypothetical gene \\
\hline AA203545 & 1.9 & Unknown \\
\hline
\end{tabular}

immunodeficiency. Previous studies have shown the ability of HIV-1 Nef to decrease the expression of CD4, HLA$A$, and HLA-B, while having no effect on HLA-C or HLA$\mathrm{D}$, which allows for host cell survival and permits productive viral progeny formation prior to immune recognition and eventual apoptosis [22,23]. HLA-A and HLA-B allow for efficient CD8 ${ }^{+}$cytotoxic T lymphocyte (CTL) detection. Since it has been demonstrated that HLA-C and HLA-E are needed for protection from natural killer (NK) cell-mediated death [23], the up-regulation of HLA-C by Tat suggests similar host cell survival-directed functions for both Tat and Nef. Interestingly, HLA-G has been shown to be up-regulated in both monocytes and $\mathrm{T}$ lymphocytes of seropositive individuals, though its relation to infection and pathogenesis remains to be determined [24].

Collectively, SOM and k-means analyses catalog a set of genes representative of a close interplay between promoting and inhibiting factors induced by Tat. These findings, coupled with the up-regulation of signaling receptors involved in cell growth and survival, illustrate an intrinsic ability of HIV-1 Tat in regulating immune evasion, viral transmission, cell cycle progression and subsequent apoptosis. Importantly, these results delineate a variety of cellular gene products, both previously characterized with respect to HIV-1 and those uncharacterized, to be directly or indirectly induced by Tat expression. A plausible notion is that during activated transcription, HIV-1 hijacks the host cell machineries to promote its own replication, while concurrently directing a certain minimal level of cell survival until the virus reaches its critical point of progeny formation and subsequent virus-induced cell cycle block and apoptosis at the $\mathrm{G}_{2}$ phase.

\section{siRNA-mediated validation of cellular HIV-I therapeutic targets}

Using siRNAs targeted at several Tat-induced host cellular gene products, we examined the significance of our synchronized microarray data on a few genes we thought were critical for productive viral progeny formation. Based on the 32 arrays (16 eTat and 16 pCep4) in this study, we generated a list of Tat-induced genes that included those genes displaying two or more present calls on the eTat chips (present on at least 2 of 16 chips) while having 16 absent calls in the control pCep4 chips. We hypothesized that genes which were consistently (at various cell cycle phases) induced/repressed by Tat and were absent from the control pCep4 chips, would be the most important and specific for the Tat-mediated effects on the viral life cycle or host cell cycle progression. We also identified genes that displayed at least four and at least eight present calls across all 16 eTat chips and displayed all absent calls across all 16 pCep4 chips [see Additional File 4 and Methods]. Finally, the two present call gene list was screened against the Hu95 microarray data indexed at the Children's National Medical Center (CNMC) in Washington, D.C. This analysis was executed to identify those genes only induced by Tat, while never induced in a myriad of other human genetic diseases and tissues whose data is hosted at CNMC. Those genes that were $100 \%$ absent or $50.1 \%$ to $99.9 \%$ absent across all the Hu95 data in the database were compiled and listed (Table 2). This list of genes has potential to be very specific cellular therapeutic targets.

Based on a literature search of our initial list of dysregulated genes (from the K-means, SOMs, and present call gene list analyses) and from the CNMC screen, we have a comprehensive list of potential targets. Through the exhaustive literature search, we looked for genes that were previously characterized as necessary for HIV-1 replication and/or progeny formation and identified HIV-1 Rev 
binding protein 2, Pou2AF1 (OBF-1), cyclin A1, PPGB, EXT2, and HEXA for further analysis. The HIV-1 Rev binding protein 2 has been characterized as having high homology to the $S$. cerevisiae Krr1p protein, which is a nucleolar protein, and has been shown to be critical for $18 \mathrm{~S}$ rRNA synthesis and subsequent $40 \mathrm{~S}$ ribosome synthesis and cell viability [25-27]. Therefore, ablation of the HIV-1 Rev binding protein 2 should theoretically inhibit virus replication and possibly direct infected cells towards apoptosis. The HIV-1 LTR contains four potential binding sites for the Oct-1 transcription factor and Oct-1 has been shown to interact with Tat [28]. OBF-1 interacts with Oct1 and Oct-2, acting as a B lymphocyte-specific transcriptional coactivator of B cell activation and maturation, as well as induction of immunoglobulins. It is also activated in T cells upon TCR signaling [29]. Recently, OBF-1 was found to up-regulate CCR5 co-receptor surface expression and fusion to the Env protein of R5 strains, the predominant strain found during initial infection [29]. Therefore, we predict that this factor is repressed upon the onset of AIDS, which is usually correlated with a R5 to X4 HIV-1 strain switch. Cyclin A1, which binds and regulates cdk2 and cdk1, was also chosen for targeted inhibition since it is important during the $S$ and $G_{2}$ phases of the cell cycle, both of which are important for the viral life cycle $[5,30]$. Cyclin A1 has also been shown to bind Rb family members, the p21/waf1 family of endogenous cdk inhibitors, as well as the E2F-1 transcription factor, all of which are important in the regulation of cell cycle progression and HIV-1 progeny formation [4,6,31-34].

Based on the importance of viral attachment, entry, and membrane fusion in the course of infection, we also chose to inhibit expression of the PPGB protein, which forms a heterotrimeric complex with the lysosomal enzymes $\beta$ galactosidase and neuraminidase (NA). Though there have been no reports on the contribution of PPGB in HIV1 infection, a number of reports have illustrated the importance of NA in increasing the efficiency of viral binding and entry $[35,36]$. NA is a sialidase that exposes sites on the HIV-1 gp120 surface protein, enabling greater interaction between gp120 and the CD4/co-receptor complex, which consequently increases syncytium formation and single-round infection by both X4 and R5 HIV-1 isolates. These findings coupled with the importance of HSPGs, illustrate the importance of membrane proteins and their modifications on both viral attachment and entry processes. Cellular proteins involved in the fusion and entry processes of infection may play a greater role in extracellular Tat-mediated effects, such as bystander cell infection.

The EXT2 and HEXA gene products were also targeted since they displayed present calls in at least half of the eTat chips and showed no induction in the pCep4 chips [see
Additional File 4]. EXT2 is a putative tumor suppressor with glycosyltransferase activity that is involved in the chain elongation step of heparan sulfate biosynthesis [37]. HEXA is involved in ganglioside GM2 degradation and is a member of a subfamily of glycosyl hydrolases [38]. It has been established that GM2 levels are significantly increased in HIV-1 infection, as is seen both in vitro and in vivo from seropositive individuals [39,40]. Surprisingly, both groups showed that anti-GM2 IgM antibodies caused complement-mediated cytolysis of infected cells. We propose that inhibiting HEXA would increase the levels of circulating GM2 in vivo, thereby creating a more pronounced level of infected cell cytolysis.

Using HIV-1 latently infected OM 10.1 T cells, which contain a single copy of silent full length wild type infectious provirus, we transfected $10 \mu \mathrm{g}$ of each siRNA (2 for each representative gene) into cells. After 48 hrs, TNF- $\alpha$ was added for 2 hours to induce the latent virus and normal cell cycle progression. Samples were collected at $72 \mathrm{hrs}$ post-TNF- $\alpha$ treatment and subjected to p24 Gag ELISA and western blot analysis. Cells that were not transfected with any siRNA were used as the negative control sample, while cdk2 and cdk9-targeted siRNAs served as positive controls. As seen in Figure 5A, the majority of siRNAs demonstrated some efficacy in inhibiting p24 expression. Ablation of EXT2 had a moderate effect ( $\sim 2$ fold reduction), while the HEXA siRNA had a negligible effect $(<1$ fold reduction). While the $\mathrm{cdk} 2$ - and cdk9-mediated inhibition of HIV-1 replication was expected [41,42], the potency of the other siRNAs were very dramatic. Interestingly, the most effective siRNAs were involved in cell cycle progression and/or transcription (cdk2, cdk9, cyclin A1, and OBF-1), RNA pathways (HIV-1 Rev binding protein $2)$, or membrane protein modification (PPGB). While EXT2 has been shown to be important in heparan sulfate synthesis, HSPGs are most important for cells that do not express large amounts of CD4, such as macrophages [20]. Thus, EXT2 degradation should only affect infection and replication in cells devoid of CD4.

We also performed series of western blots to measure the efficiency of inhibition from each of siRNAs tested. As shown in Figure 5B most siRNA treatments dropped the protein level by more than 90\%, except for the HEXA gene. None of siRNAs inhibited actin gene expression or PARP degradation (an indicator of active apoptosis), implying that the siRNA targets were not toxic in these transient experiments. We finally performed simple FACS analysis using PI staining and saw no apparent cell cycle or apoptotic effects (Figure 6). Although, we have never been able to inhibit HEXA translation completely in OM10.1 cells (or three other infected cell lines), data on HEXA indicates that even a $50 \%$ drop in protein levels 
A)

B)
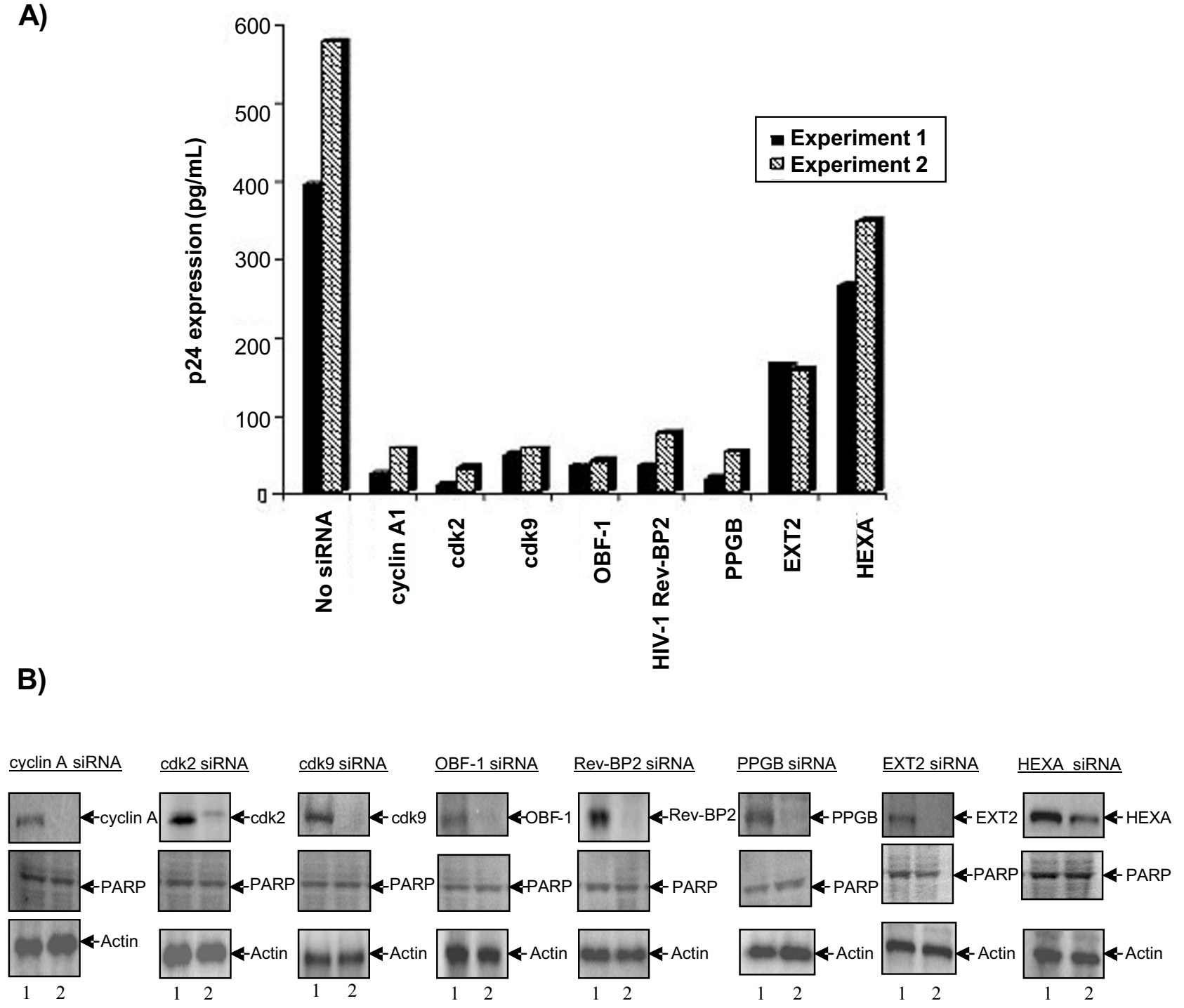

Figure 5

Representative siRNA-directed inhibition of HIV-I replication. (A) Using two candidate siRNAs per gene shown, each siRNA was transfected into HIV-I latently infected OM-I0.I cells at mid log phase of growth. Following transfection, viral activation, and treatment, supernatants were collected and analyzed for p24 Gag expression by ELISA. The white crossed bars represent the first set of experiments, while the black bars represent the second run performed in an identical manner. (B) For Western blots, protein samples (one hundred micrograms of each extract) were separated on SDS-PAGE and then transferred to an Immobilon-P (polyvinylidene difluoride; Millipore) membrane and blocked with $5 \%$ fat-free milk (in TNE50/0. I\% Nonidet $\mathrm{P}-40)$. Membranes were incubated overnight with various primary antibodies, and reactive complexes were developed with protein G-labeled ${ }^{125}$ and visualized with a Phosphorlmager scanner (Amersham Biosciences).

maybe sufficient to increase GM2 levels, thereby increasing a more pronounced rate of viral production.

Next, we performed a similar set of experiments in PBMCs infected with a HIV-1 field isolate and treatment with var- ious siRNAs. Activated PBMCs were first treated with 10 $\mu \mathrm{g}$ of each siRNA for 48 hours and subsequently infected with a field HIV-1 isolate (UG/92/029 Uganda strain, subtype A envelope). Supernatants were collected every six days for Gag p24 assay. Results in Figure 7A indicate that 

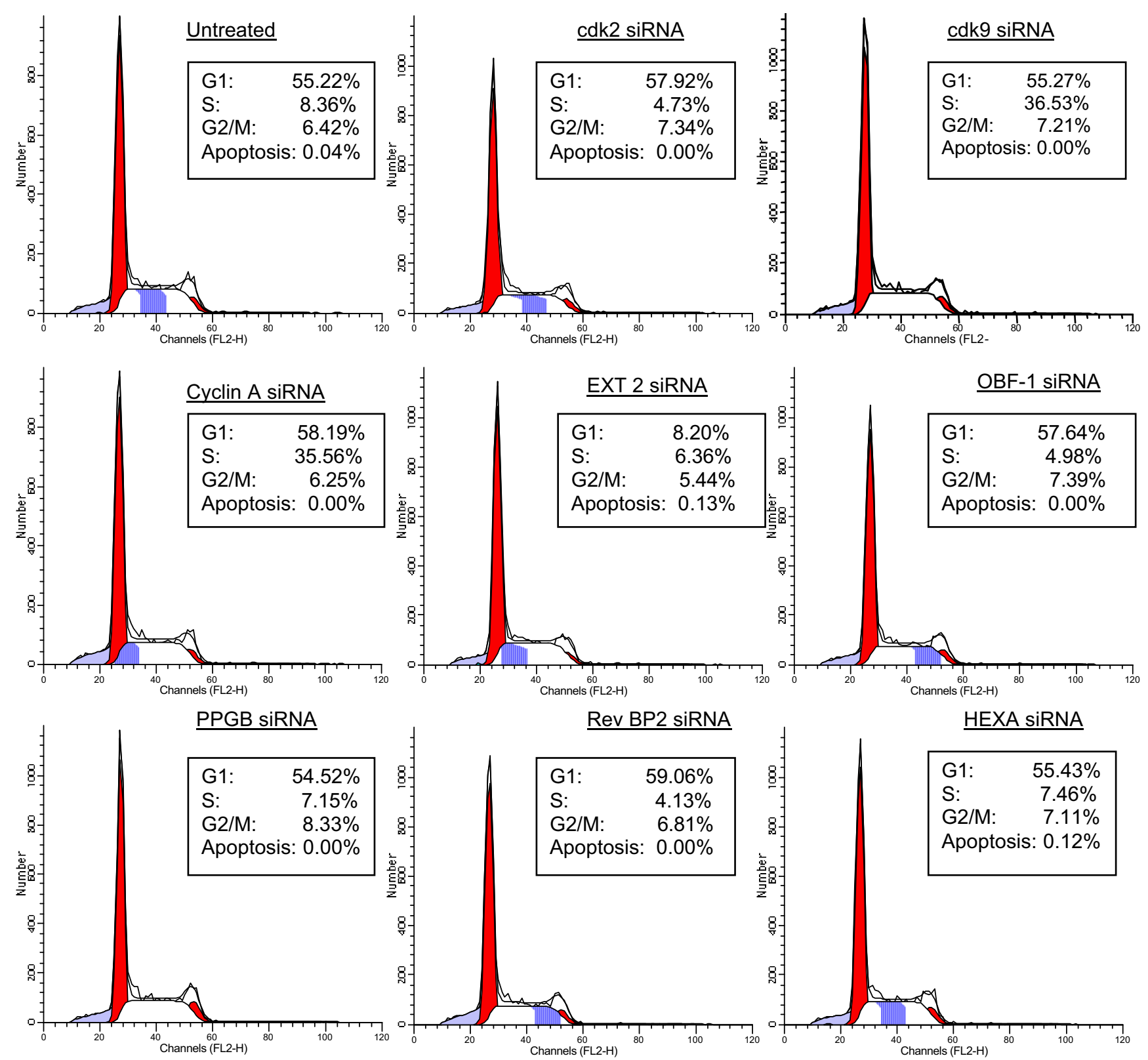

Figure 6

FACS analysis of PI stained OMI 0.1 cells. The stained cells were analyzed for red fluorescence (FL2) on a FACScan (Becton Dickinson, San Jose, $C A$ ), and cell distribution in the $G_{1}, S$, and $G_{2} / M$ phases of the cell cycle was calculated from the resulting DNA histogram with Cell FIT software, based on a rectangular S-phase model. A sub-GI population was considered as an apoptotic population.

siRNA's against cdk9, cdk2, HEXA, and Rev-BP2 were the most potent inhibitors, followed by siRNAs against cyclin A, OBF-1 and PPGB, and the least amount of inhibition with EXT-2 siRNA. Control experiments using antibody staining against CD4 on activated PBMCs treated with each siRNA for 48 hours prior to HIV-1 infection showed no appreciable differences, except a minor drop with cdk2 siRNA ( $5 \%)$ in CD4 levels (Figure 7B), and a PI staining of the same cells also showed no significant apoptosis except for a minor drop with cyclin A siRNA ( $\sim 5 \%$, Figure $7 \mathrm{C}$ ), implying that the siRNA treatment in general did not significantly alter the expression of CD4 levels prior to 
viral infection. Collectively, these results are somewhat similar to the latent OM10.1 treatments and imply that these genes could be a potential target in both cell lines and primary infections.

Finally, we asked whether the identified gene lists from our siRNA experiments were specific to HIV-1 transcription or could they also inhibit other viral activated transcriptions. We therefore performed CAT assays with either HIV-LTR-CAT and its activator Tat (as positive controls, Figure 8, Lanes 1-3) or HTLV-LTR-CAT and its positive activator Tax (Figure 8, lanes 4-14). Results in Figure 8 show that HIV-1 activated Tat can be suppressed with cdk2, however none of the siRNA treatments inhibited HTLV-1 Tax activated transcription except cdk9 siRNA. This result is somewhat expected since cdk9 is known to be involved in general transcription elongation, and is consistent with a recent report indicating that Tax might have a role in transcription elongation $[43,44]$.

\section{Conclusion}

Potential therapeutic targets of HIV-I Tat-induced cellular genes

We believe that our current results are by no means the ultimate list of genes altered by HIV-1 Tat. Some of the limitations of our experiments include: constant presence of Tat in cells as compared to possible transient expression of Tat in HIV-1 infected cells, possible indirect effect of Tat on gene expression, and lack of using various Tat clades (i.e., from clades B, E, and C), which may have a different rate and set of activated genes in vivo. However, we believe the current study is an ongoing attempt to narrow down which cellular genes are critical in Tat regulation and therefore define a minimal set of potential targets for therapy.

Based on exhaustive and stringent data analysis, we have compiled a list of gene products that may serve as potential therapeutic targets for the inhibition of HIV-1 replication (Table 1 and 2). Table 1 specifies Tat-induced cellular genes at the $G_{1} / S$ transition, while Table 2 lists those genes that were observed to be up-regulated by Tat while displaying no induction in the myriad of genetic diseases and diverse tissues and cell types screened at CNMC. As observed in both tables and the initial screening of genes displaying at least two present calls, several genes have been established as important for HIV-1 infection and replication, including OBF-1 [29,45], complement factor $\mathrm{H}$ related 3 [46], CD4 receptor, ICAM$1[18], \mathrm{NA}[35,36]$, and cyclin A1 $[8,47]$.

There were also several genes that have not been published in relation to HIV-1 infection and may also be novel and efficacious therapeutics. These include FGFR and EGFR, the latter of which has been targeted against various cancers and inhibits cancer-associated angiogenesis and subsequent metastasis [48]. Concerning HIV-1 infection and replication, some potentially important proteins that have not been previously characterized with respect to HIV-1 and thus necessitate further study, seem to be the CAP-binding protein complex interacting protein, tropomyosin 2 beta, BTG3, the IL-10R, PPGB, and cathepsins $\mathrm{Z}$ and L2 [see Additional File 4 and Tables 1 \&2]. Though not established, the CAP-binding protein complex is most likely involved in translation processes. Tropomyosin 2 beta was found to interact with FRP1, which is important in the regulation of HIV-1 virus-mediated cell fusion and possibly syncytium formation [49]. Also, therapeutics against individual gene products or a cocktail containing inhibitors for ICAM-1, LFA-3, DCSIGN, all syndecan isoforms, PPGB, clusterin and other adhesion/membrane proteins important in viral transmission may, alone or in combination with Fuzeon/T20, significantly abrogate the infection of circulating lymphocytes and other cells that are able to support viral infection and replication.

Recently a report by Krishnan and Zeichner described experiments associated with changes in cellular gene expression that accompany the reactivation of the lytic viral cycle in cell lines chronically infected with HIV-1. They found that several genes exhibited altered expression in the chronically infected cells compared to the uninfected parental cells prior to induction into lytic replication including genes encoding proteasomes, histone deacetylases, and many transcription factors [50]. Although it is difficult for us to compare our results with Krishnan and Zeichner due to difference in cell types, presence of all HIV-1 ORFs as compared to our study where there was only Tat present, and the difference in cell cycle stages, however, we did a general comparison and found some overlap between our list of dysregulated genes and theirs - this overlap includes genes coding for splicing factors, proteasomes, and heat shock proteins. We compared our SOM and k-means analyses (Table 1) from which we found genes that displayed differential expression at the G1/S phase and found three intersecting genes as well as some genes that are very closely related to genes listed in the Krishnan table (e.g. genes coding for a different subunit of a protein); these genes are listed in Table 3. The first part of Table 3 contains three genes that fell in both our SOM and k-means analyses and the Krishnan table (bold genes) and the genes from our SOM and kmeans analyses that are closely related to genes in the Krishnan table. Collectively, the list of common genes indicates the involvement of HIV-1 Tat in splicing, transport of RNA, an acceleration of cell cycle stages. All of these genes fall into pathways that have previously been reported to be regulated by Tat, including stabilization of critical transcription units (i.e., Hsp70 stabilization of 
A)

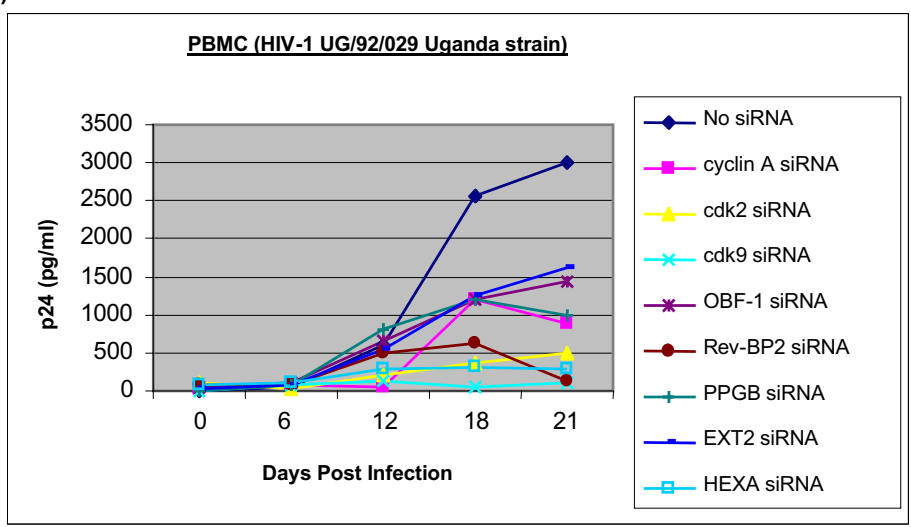

B)

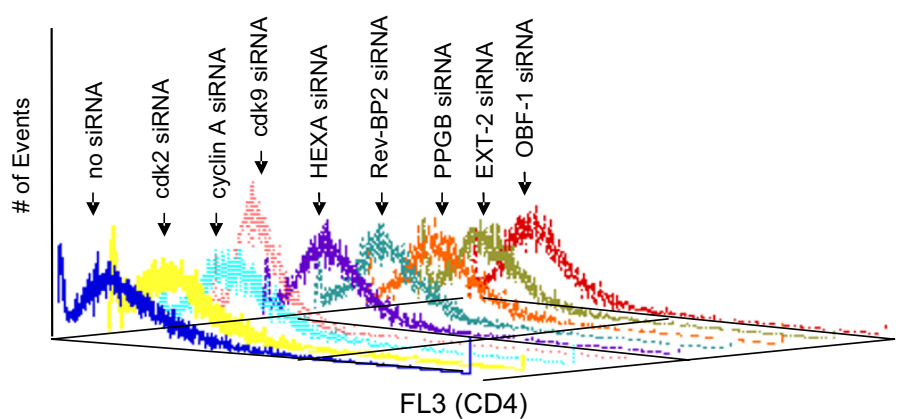

C)

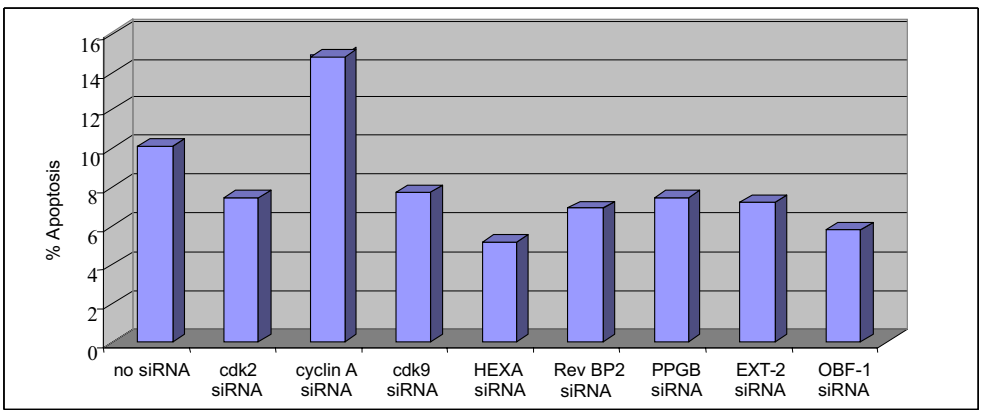

Figure 7

Effect of representative siRNA treatment in PBMC field isolate HIV-I infection. Approximately $5 \times 10^{6} \mathrm{Phytohe-}$ magglutinin-activated PBMC were kept in culture for two days prior to infection. PBMC were first treated for 48 hrs with 10 $\mu g$ of the various siRNAs and then infected with SI (UG/92/029 Uganda strain, subtype A envelope, $5 \mathrm{ng}$ of p24 gag antigen) strain of HIV-I obtained from the National Institutes of Health (NIH) AIDS Research and Reference Reagent Program. After 8 $\mathrm{h}$ of infection, cells were washed and fresh media was added. Samples were collected every sixth day and stored at $-20^{\circ} \mathrm{C}$ for p24 gag enzyme-linked immunosorbent assay (ELISA). Media from infected cell lines was centrifuged to pellet the cells and supernatants were collected and diluted to 1 : 100 to $1: I, 000$ in RPMI 1640 prior to analysis. Supernatants from the infected PBMC were collected and used directly for the p24 antigen assay. The p24 gag antigen level was analyzed using the HIVAG-I Monoclonal Antibody Kit (Abbott Laboratories, Diagnostics Division). (B) PBMCs stimulated with PHA were treated with appropriate siRNA prior to HIV infection and stained for presence of surface CD4 on activated cells. Prior to infection, I/5 of the samples were processed for CD4 and PI staining. Cells were then collected and washed twice with PBS containing FCS and $\mathrm{NaN}_{3}$. Cells were stained on ice for with human tri-color-labeled anti-CD4 (Catalog Laboratories) at a I:I0 dilution. Stained cells were next washed two times in PBS containing FCS and $\mathrm{NaN}_{3}$ and fixed in paraformaldehyde followed by analysis by FACS. (C) FACS analysis of PI stained cells from panel B. Sub-GI population was scored as apoptotic population in each siRNA treated cell. 


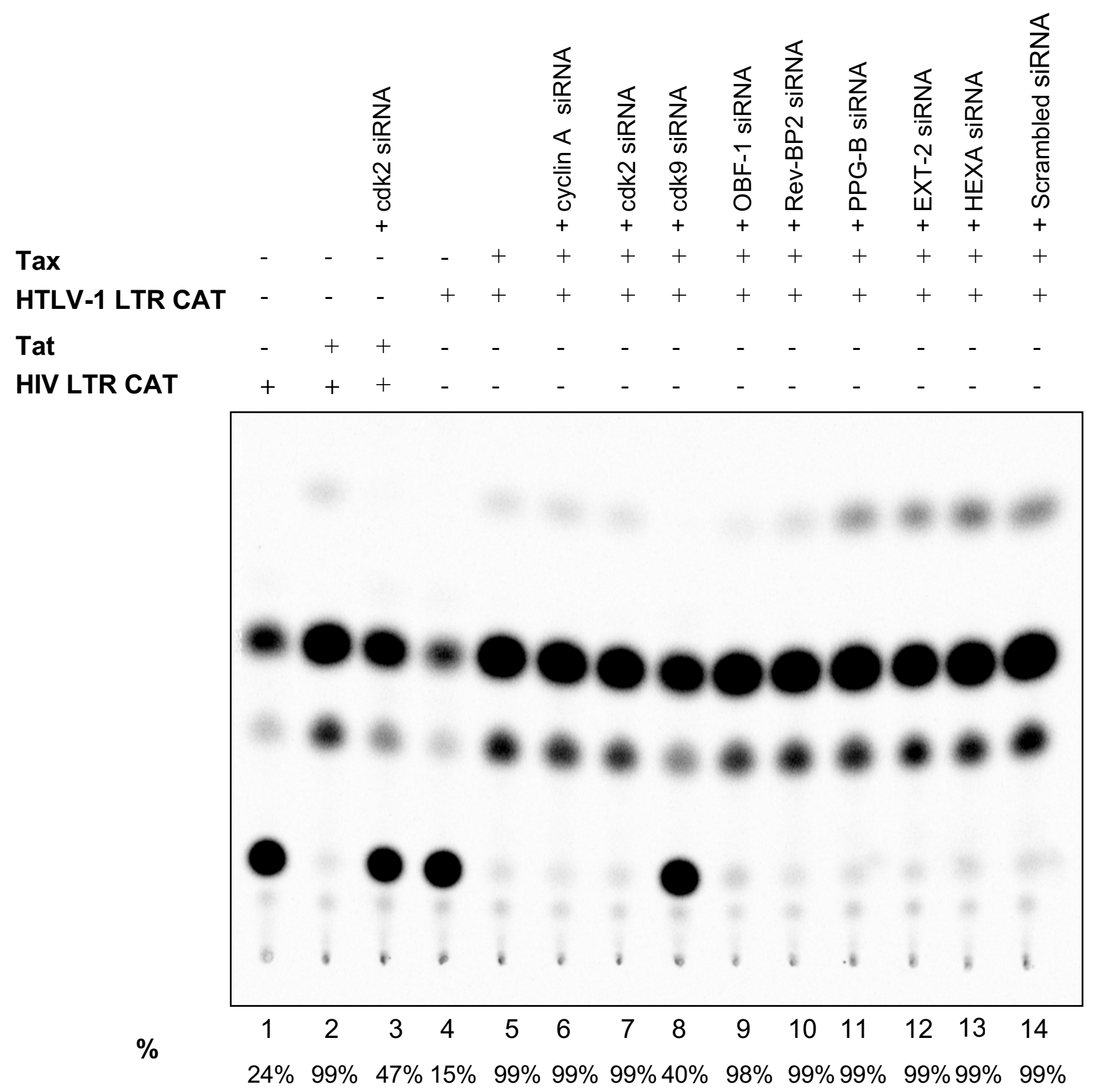

\section{Figure 8}

CAT assays with HIV-LTR-CAT and its activator Tat, and HTLV-LTR-CAT and its positive activator Tax. Lymphocyte (CEM, I2D7) cells were grown to mid log phase and were processed for electroporation according to a procedure published previously [52]. The cells were washed with phosphate-buffered saline and resuspended in RPMI I640. They were next transfected with reporter constructs (HIV-LTR-CAT or HTLV-LTR-CAT; 3 ug of each), their respective activators (Tat or Tax; 4 ug each) or with various siRNAs (I0 ug each). Lanes I-3 serve as positive controls for basal, activated transcription and effect of cdk2 siRNA on inhibition of HIV-I LTR. Lanes 4-I4 are basal, activated transcription and effect of various siRNAs on HTLV- LTR-CAT. Only cdk9 siRNA showed an appreciable amount of suppression on Tax activated HTLV-LTR (lane 8). CAT \% conversations are listed below the diagram. 
Table 3: A set of common genes regulated by Tat in both Tat expressing cells and HIV-I infected cells.

\begin{tabular}{|c|c|c|}
\hline Probe Set ID & Accession \# & Gene Description \\
\hline 34083_at & AA3III8I & splicing factor, arginine/serine-rich 9 \\
\hline 35323_at & U78525 & eukaryotic translation initiation factor 3 , subunit 9 (eta, I I6 kD) \\
\hline 31858_at & $\times 07315$ & nuclear transport factor 2 \\
\hline 32165_at & L4I887 & splicing factor, arginine/serine-rich 7 (35 kD) \\
\hline 32556_at & $\times 64044$ & U2 (RNU2) small nuclear RNA auxiliary factor 2 \\
\hline 33372_at & All 89226 & RAB3I, member RAS oncogene family \\
\hline 39628_at & Al67I547 & RAB9A, member RAS oncogene family \\
\hline 2029_at & N36267 & Rho GTPase activating protein 5 \\
\hline 35255_at & AF098799 & RAN binding protein 7 \\
\hline II91_s_at & $\mathrm{AB} 003102$ & proteasome (prosome, macropain) 26S subunit, non-ATPase, II \\
\hline $1192 \_$at & $\mathrm{AB} 003103$ & proteasome (prosome, macropain) 26S subunit, non-ATPase, 12 \\
\hline 37350_at & AL03II77 & proteasome (prosome, macropain) 26S subunit, non-ATPase, 10 \\
\hline I 104_s_at & MII7I7 & heat shock $70 \mathrm{kD}$ protein IA \\
\hline 36614_at & X87949 & heat shock 70 kD protein 5 (glucose-regulated protein, 78 kD) \\
\hline 35467_g_at & W73046 & DnaJ (Hsp40) homolog, subfamily B, member 12 \\
\hline
\end{tabular}

Cdk9/cyclin T1 complex), splicing and nuclear transport (i.e., the SR protein ASF/SF2; Tat-SF1), translation (5'-terminal TAR recognition by eukaryotic translation initiation factor 2), and degradation of critical factors needed for cell cycle progression using the proteosome pathway (i.e., analogous to HPV E6 binding to p53 and its degradation resulting in loss of check point, ubiquitin/proteasome degradation of IkappaB(alpha) and release of active NFkB, or CD4 glycoprotein degradation through the ubiquitin/proteasome pathway). Therefore these results imply that Tat regulates these apparently discrete pathways, at least in case of pre-mRNA processing, where transcription initiation/early elongation complex directly controls every aspect of subsequent pre-mRNA processing including capping at the $5^{\prime}$ end, intron recognition and removal by splicing, the 3' end cleavage and polyadenylation, and release of the mature mRNA from the site of transcription and export to the cytoplasm for translation [51].

While some of these proteins have available inhibitors, the majority of the potential cellular targets for HIV-1 therapeutics do not have known specific inhibitors. Thus, much effort must be allocated for the elucidation and design of specific inhibitors, concurrent with the growing plausibility of siRNA-based therapeutics. Another important factor in designing inhibitors for cellular targets, as shown with potential cancer therapeutics, is the necessity to target cellular gene products with redundant functions. If a certain cellular protein kinase, receptor, membrane protein, or cytokine/chemokine is inhibited, it may have adverse effects that make the drug impractical for clinical trials and use. However, the presence of two or more proteins with similar functions, with only one being critical for HIV-1 and thus targeted, may allow for the decreased possibility of side effects. This is especially true for target- ing redundant molecules (i.e., cdk2), where they are nonessential during mammalian development and are likely replaced by other kinases. Similarly, once specific inhibitors are elucidated, a major resulting challenge is generating a combinatorial therapeutic regimen that is effective in sub-lethal doses (submicromolar or nanomolar range).

\section{Methods \\ Cell culture}

HeLa CD4+ cells containing either an epitope-tagged (the influenza epitope at the $C$ terminus of Tat 1-86) eTat plasmid or the parental control vector pCep4 were used [2]. All cells were cultured in RPMI 1640 containing 10\% fetal bovine serum, $1 \%$ streptomycin/penicillin, and $1 \% \mathrm{~L}$ glutamine (Quality Biological) at $37^{\circ} \mathrm{C}$ in $5 \% \mathrm{CO}_{2}$.

\section{Cytoplasmic RNA isolation}

Cells were centrifuged at $4^{\circ} \mathrm{C}, 3000 \mathrm{rpm}$ for $10 \mathrm{~min}$., quickly washed with D-PBS without $\mathrm{Ca}^{2+} / \mathrm{Mg}^{2+}$, and centrifuged twice. Pelleted cells were immediately frozen at $-80^{\circ} \mathrm{C}$ until all time points were collected. Cytoplasmic RNA was isolated utilizing the RNeasy Mini Kit (Qiagen, Valencia, CA) according to manufacturer's directions with the addition of $1 \mathrm{mM}$ dithiothreitol in Buffer RLN. Isolated RNA was quantitated by UV spectrophotometric analysis and $3 \mu \mathrm{g}$ of RNA was visualized on a non-denaturing $1 \%$ agarose TAE gel for quality and quantity control.

\section{Lymphocyte Transfection}

Lymphocyte (CEM, 12D7) cells were grown to mid log phase and were processed for electroporation according to a procedure published previously [52]. The cells were centrifuged and then washed with phosphate-buffered saline without $\mathrm{Mg} 2+$ or $\mathrm{Ca} 2+$ twice and resuspended in RPMI 
1640 at $4 \times 10^{5}$ cell $/ 0.25 \mathrm{ml}$. The CEM cells $(0.25 \mathrm{ml})$ were transfected with the plasmid DNAs of HIV-LTR-CAT or HTLV-LTR-CAT ( 3 ug of each) either alone or in combination with Tat or Tax (4ug each). $10 \mu \mathrm{g}$ of the various siRNAs were also mixed in with reporter and/or appropriate transactivator prior to electroporation. The mixture of cells, plasmid DNAs, and siRNAs were then transferred to a cuvette and electroporated with fast charge rate, at 230 $\mathrm{V}$, and capacitance of 800 microfarads. Cells were then plated in $10 \mathrm{ml}$ of complete RPMI 1640 medium for $18 \mathrm{~h}$ prior to harvest and CAT assay. For CAT assays, standard reaction was performed by adding the cofactor coenzyme A to a microcentrifuge tube containing cell extract and radiolabeled chloramphenicol, in a final volume of $50 \mu \mathrm{l}$ and incubated at $37^{\circ} \mathrm{C}$ for $1 \mathrm{~h}$. The reaction mixture was then extracted with ethyl acetate. It was then separated by TLC on silica gel plates (Baker-flex silica gel TLC plates) using the chloroform:methanol (19:1) solvent system. The resolved reaction products were then detected by exposing the plate to a PhosphorImager cassette.

\section{Immunoprecipitation/Western Blot Analysis}

Immunoprecipitations of tat protein were performed as described previously [2]. Cellular protein $(100 \mu \mathrm{g})$ was mixed with monoclonal 12CA5 antibody $(2.5 \mu \mathrm{g})$ for $2 \mathrm{~h}$ at $4{ }^{\circ} \mathrm{C}$. Protein $\mathrm{A}+\mathrm{G}$ agarose beads ( $5 \mu \mathrm{l}$; Calbiochem, Inc.) were added and incubated at $4{ }^{\circ} \mathrm{C}$ for another $2 \mathrm{~h}$. The immunoprecipitated complex was then spun down and washed with buffer D containing $500 \mathrm{mM} \mathrm{KCl}$ (three times; $1 \mathrm{ml}$ each). Samples were eluted with HA- peptide for 4 hrs at $37 \mathrm{C}$ on a rotator, and eluted complexes were separated on a 4-20\% SDS-polyacrylamide gel electrophoresis gel, and Western blot analysis was performed with anti-Tat monoclonal antibody. Antigen/antibody complexes were detected with ${ }^{125}$ I Protein G.

\section{CD4 staining of human cells}

Human PBMCs stimulated with PHA were treated with appropriate siRNA prior to HIV infection. Activated PBMCs were first treated with $10 \mu \mathrm{g}$ of each siRNA for 48 hours and subsequently infected with a field HIV-1 isolate (UG/92/029 Uganda strain, subtype A envelope, $5 \mathrm{ng}$ of p24 gag antigen) [53]. Prior to infection, 1/5 of the samples were processed for CD4 and PI staining. Cells were then collected and washed twice with PBS containing 5\% FCS and $0.05 \% \mathrm{NaN}_{3}$. Cells were stained on ice for 30 minutes with human tri-color-labeled anti-CD4 (Catalog Laboratories) at a 1:10 dilution. Stained cells were next washed two times in PBS containing 5\% FCS and 0.05\% $\mathrm{NaN}_{3}$ and fixed in 1\% paraformaldehyde followed by analysis by FACS.

\section{Cell cycle analysis}

The eTat and pCep4 cells were either blocked with hydroxyurea $\left(\mathrm{G}_{1} / \mathrm{S}\right.$ blocker, $\left.2 \mathrm{mM}\right)$ or nocodazole $\left(\mathrm{G}_{2} / \mathrm{M}\right.$ blocker,
$50 \mathrm{ng} / \mathrm{ml}$ ). Cells were washed with PBS and released with complete medium. Samples were collected every $3 \mathrm{hrs}$ and cytoplasmic RNA was isolated. Single-color flow cytometric analysis of DNA content (PI staining) was performed on both cell types [2]. Stained cells (including OM10.1) were analyzed for red fluorescence (FL2) on a FACScan (Becton Dickinson, San Jose, CA), and cell distribution in the $G_{1}, S$, and $G_{2} / M$ phases of the cell cycle was calculated from the resulting DNA histogram with Cell FIT software, based on a rectangular S-phase model.

\section{PBMC infection}

Phytohemagglutinin-activated PBMC were kept in culture for two days prior to each infection. Isolation and treatment of PBMC were performed by following the guidelines of the Centers for Disease Control. Approximately $5 \times 10^{6}$ PBMC were first treated for 48 hrs with 10 $\mu \mathrm{g}$ of the various siRNAs and then infected with SI (UG/ 92/029 Uganda strain, subtype A envelope, $5 \mathrm{ng}$ of p24 gag antigen) strain of HIV-1 obtained from the National Institutes of Health (NIH) AIDS Research and Reference Reagent Program. After 8 h of infection, cells were washed and fresh media was added. Samples were collected every sixth day and stored at $-20^{\circ} \mathrm{C}$ for p 24 gag enzyme-linked immunosorbent assay (ELISA). For HIV-1 p24 ELISA, media from infected cell lines was centrifuged to pellet the cells and supernatants were collected and diluted to 1:100 to $1: 1,000$ in RPMI 1640 prior to analysis. Supernatants from the infected PBMC were collected and used directly for the p24 antigen assay. The p24 gag antigen level was analyzed using the HIVAG-1 Monoclonal Antibody Kit (Abbott Laboratories, Diagnostics Division).

\section{siRNA analysis}

siRNA sequences were designed using the Oligoengine Workstation http://www.oligoengine.com and were purchased from Qiagen-Xeragon. Candidate sequences were chosen based on general siRNA design criteria, including a \%GC content between 45-55 \% and avoiding more than three consecutive guanosines. Selected target sequences were also BLASTed http:// www.ncbi.nlm.nih.gov/BLAST/ with a standard nucleotide-nucleotide BLAST to ensure they were not homologous to other genes. Each candidate siRNA was generated from the $5^{\prime}$ end and consisted of 19 nucleotides with a $\mathrm{d}(\mathrm{TT})$ overhang.

The following genes were chosen for siRNA analysis with the GenBank accession numbers in brackets: HIV-1 Revbinding protein 2 [U00943], Pou2AF1 (OBF1) [Z49194], cyclin A1 [U66838], PPGB [NM_000308], cdk2 [AF512553], cdk9 [AF517840], EXT2 [U67368], and HEXA [M16424]. 2 candidate siRNAs were chosen for each of the 8 genes to ensure protein expression silencing. For each duplex siRNA, the first sequence represents the 
sense sequence ("s"), and the second, the antisense sequence ("as"):

HIV-I Rev-binding protein 2

1. s: GGUCCAAUGGCUGAAACUG, as: CAGUUUCAGCCAUUGGACC

2. s: ACAGUCAUGCUGCCUUCGA, as: UCGAAGGCAGCAUGACUGU

Pou2AFI (OBF-I)

1. s: GAGGAUAGCGACGCCUAUG, as: CAUAGGCGUCGCUAUCCUC

2. s: UGUCACGACAAGAAGCUCC, as: GGAGCUUCUUGUCGUGACA

\section{Cyclin AI}

1. s: ACUGCAGCUCGUAGGAACA, as: UGUUCCUACGAGCUGCAGU

2. s: GUAGACACCGGCACACUCA, as: UGAGUGUGCCGGUGUCUAC

\section{PPGB}

1. s: CUAAUGACACUGAGGUCGC, as: GCGACCUCAGUGUCAUUAG

2. s: UGCGUGACCAAUCUUCAGG, as: CCUGAAGAUUGGUCACGCA

\section{Cdk2}

1. s: AUCCGCCUGGACACUGAGA, as: UCUCAGUGUCCAGGCGGAU

2. s: UCCUCCUGGGCUGCAAAUA, as: UAUUUGCAGCCCAGGAGGA

\section{Cdk9}

1. s: CCACGACUUCUUCUGGUCC, as: GGACCAGAAGAAGUCGUGG

2. s: CCGCUGCAAGGGUAGUAUA, as: UAUACUACCCUUGCAGCGG

\section{EXT2}

1. s: GCACCUCGAGCUAUGCAAC, as: GUUGCAUAGCUCGAGGUGC

2. s: CUCCGUCUUUGGCCUGACA, as: UGUCAGGCCAAAGACGGAG

\section{HEXA}

1. s: CCUGGUCACAAAAGAGCCU, as: AGGCUCUUUUGUGACCAGG

\section{2. s: GUGUGAAUGGCGUUAGGGU,} as: ACCCUAACGCCAUUCACAC

HIV-1 latently infected OM-10.1 T lymphocytes were treated with $10 \mu \mathrm{g}$ of the various siRNAs listed above for 48 hrs prior to TNF- $\alpha$ treatment. siRNAs were electroporated into OM-10.1 cells at $5 \times 10^{6}$ (mid log phase of growth) cells $/ \mathrm{ml}$. 48 hrs later cells were treated with TNF$\alpha(5 \mu \mathrm{g} / \mathrm{ml}$ for $2 \mathrm{hrs})$ to induce viral transcription and progeny formation, washed, and complete media was added to cells. Samples were collected at 72 hrs post-TNF$\alpha$ treatment for presence of HIV-1 p24 Gag by ELISA. Presence of p24 Gag in the supernatant is indicative of mature infectious virion particles released from HIV-1 infected cells.

\section{Expression profiling}

Six $\mu \mathrm{g}$ of cytoplasmic RNA from each sample were converted to double-stranded cDNA using the Superscript Choice System kit and T7-(dT)24 primer (100 pmol/ $\mu \mathrm{L})$ (Invitrogen). The cDNA was cleaned and purified using phenol/chloroform extraction and ethanol precipitation. The cDNA was then used to perform in vitro transcription using the BioArray HighYield RNA Transcript Labeling Kit (T7) (Enzo, Farmingdale, NY). The biotin-labeled cRNA was cleaned using the RNeasy Mini Kit (Qiagen) and was quantified by spectrophotometric analysis and analyzed on a $1 \%$ agarose TAE gel. The biotin-labeled cRNA was then randomly fragmented to $\sim 35-200$ base pairs by metal-induced hydrolysis using a fragmentation buffer according to the Affymetrix Eukaryotic Target Hybridization protocol. The Human U95Av2 microarrays (Affymetrix) were washed, primed, and stained on the Affymetrix Fluidics Station 400 following the Affymetrix protocol. cRNA was first detected through a primary scan with phycoerythrin-streptavidin staining and then amplified with a second stain using biotin-labeled anti-streptavidin antibody and a subsequent phycoerythrin-streptavidin stain. The emitted fluorescence was scanned using the HewlettPackard G2500A Gene Array Scanner, and the intensities were extracted from the chips using Microarray Suite 4.0 (MAS4.0) software. All raw chip data was scaled in MAS4.0 to 800 to normalize signal intensities for interarray comparisons. A statistical algorithm in MAS4.0 assigns present, marginal, and absent calls based on probe pair intensities where one probe is a perfect match of a reference sequence and the other is a mismatch probe that has a single base change at the 13 th position within the 25-base oligonucleotide reference sequence.

\section{Quality Control}

Report files generated by MAS4.0 were reviewed to ensure all quality control standards were met - these include percentage of present calls, presence of spike controls, signal scaling factors per chip, and the GAPDH 3'/5' ratios. All 
raw data files containing the signal and detection values for each probe set and supplemental data files are posted on a Translational Genomics (TGen) data site, http:// www.tgen.org/research/index.cfm?pageid=142, as well as on the Gene Expression Omnibus (GEO) online repository http://www.ncbi.nlm.nih.gov/geo as identified by GEO accession number [see Additional File 1].

\section{Data analysis}

Comparative analyses were performed in MAS4.0 between replicate samples to determine gene expression behavior changes between every sample set; calls assigned by MAS4.0 can be either increase, marginally increase, decrease, marginally decrease, or no change.

Comprehensive microarray data analysis was performed using GeneSpring software (v4.2; Silicon Genetics, Redwood City, CA). Using the synchronized cell cycle data, a gene list was generated by filtering for genes that had (1) a minimum of 2 present calls (detection as determined by MAS4.0) out of a total of 32 calls (1 call per chip), (2) a maximum p-value of 0.05 where, in this case, the p-value represents the probability that the signal intensity for a gene is due to chance alone, and (3) a greater than 2-fold expression change between control pCep4 samples and respective eTat samples. To divide the genes in this list into groups based on similar expression patterns through the cell cycle, k-means clustering (of 15 clusters as selected based on Genespring's expressed validity value) was applied and gene lists for each cluster were consolidated [see Additional Files 3 and 7].

A complementary analysis was also performed using SOMs [54]. The input gene list for this analysis was generated using several filters against the entire list of probe sets, which represent the gene transcripts on the U95Av2 array: (1) filter for at least 2 present calls, (2) any probe sets that generated an absent call across all cell cycle time points were eliminated, (3) any probe sets that did not have three out of four marginal increase or increase calls, or marginal decrease or decrease calls in at least one of the eight cell cycle time points, were removed (based on comparative analyses generated by MAS4.0) to control for replicate consistency. The signal log ratio of each gene in the resulting list was calculated (using the two replicate eTat samples and 2 replicate pCep4 samples per time point for each gene):

average signal ratio $=\frac{\text { average of } 2 \text { raw signal values for the experimental samples }}{\text { average of } 2 \text { raw signal values for the control samples }}$ Three sets of gene lists were created based on 3 separate filtering rules:

(1) $0.666<$ ratio $<1.500$
(2) $0.500<$ ratio $<2.000$

\section{(3) $0.333<$ ratio $<3.000$}

For a single rule, if a gene had average signal ratios at every time point that fell within the specified boundary, the gene was removed from the list. Separate gene lists were generated for each rule. For the first rule, 464 genes were removed and 2330 genes were used for clustering; the second rule, 1644 genes were removed and 1150 were used for analysis; and for the third rule, 2415 genes were eliminated and 379 were used for clustering. The gene ratios in each of the three lists were log transformed (natural base), median centered, applied to separate SOMs, and visualized using the U-matrix and component planes representation [for each SOM see Additional Files 5 and 6, and Figure 4, respectively] [54,55]. The algorithm incorporates a batch learning algorithm with Euclidean distance, and all computations were performed using MATLAB (The MathWorks) with the SOM-toolbox with parameters set to defaults as described [56]. Defined groups of neurons that displayed expression differences from one time point to the next in the component planes representation, as well as clusters appearing in the U-matrix were noted. Neurons in the same position across the component planes contain the same genes; thus, coloring of the neurons allows for direct interpretation of the differences in expression levels between time points. Gene lists corresponding to the first and third filters were consolidated [see 1].

The original gene list of synchronized sample data was also filtered for those genes that had all absent calls in the control cells and at least 2 present calls in the experimental cells. The resulting gene list was surveyed against 540 Affymetrix Hu95 chips whose data is hosted at the Children's National Medical Center (CNMC) in Washington, D.C. http://microarray.cnmcresearch.org. These human data include all control and experimental data produced from the study of different genetic diseases in a variety of human tissues and cultured cells. Those genes from our gene lists that were $100 \%$ absent or $50.1 \%$ to $99.9 \%$ absent across all Hu95 data in the database were compiled and noted to provide an estimate of the drug target specificity.

\section{Gene classification/ontologies}

Genes were classified as functionally relevant to HIV-1 after exhaustive literature review of publications indexed on the Entrez PubMed website. Affymetrix probe set identifiers from the increasing and decreasing expression lists were queried on the Affymetrix website http:// www.affymetrix.com using the NetAffx analysis tool to determine gene names and functions. The genes in the resulting lists were classified into ontologies to show the 
genes having increased or decreased expression (organized based on their respective functions). For the gene ontology for the entire human U95Av2 genechip, ontology lists specific to the classifications available on Genespring v5.0.3 were first obtained. The remaining classifications were queried on the Affymetrix website with the NetAffx tool http://www.affymetrix.com/analy $\underline{\text { sis/index.affx. }}$.

\section{Abbreviations}

HIV-human immunodeficiency virus

PBMC-peripheral blood mononuclear cells

HAART-highly active retroviral therapy

NNRTI-non-nucleoside reverse transcriptase inhibitor

NRTI-nucleoside reverse transcriptase inhibitor

TAR-transactivation response

Hu-hydroxyurea

Noco-nocodazole

CNMC-Children's National Medical Center

NA-neuraminidase

FGFR-fibroblast growth factor receptor

EGFR-epidermal growth factor receptor

ELISA-enzyme-linked immunosorbent assay

\section{Competing Interests}

The author(s) declare that they have no competing interests.

\section{Authors' Contributions}

WSL performed the data analyses and helped to draft the manuscript. AM, and EA performed the siRNA experiments, coordinated data analysis, and helped to draft the manuscript. TT performed the expression profiling protocol on all samples. CdlF isolated RNA and contributed to the expression profiling experiment. $\mathrm{KK}, \mathrm{CdlF}$, and SD helped with the gene expression profiling, westerns, and FACS. SH ran the self-organizing map analyses. AP provided some of the supervision for the manuscript and support for the Kashanchi lab members. DAS coordinated the expression profiling and analytical methodology. FK participated in the design, coordination, and validation of the study. DAS and FK funded the studies. All authors have read and approved the manuscript.

\section{Additional material}

\author{
Additional File 1 \\ GEO accession numbers for each sample \\ Click here for file \\ [http://www.biomedcentral.com/content/supplementary/1742- \\ 4690-2-20-S1.xls]
}

\section{Additional File 2}

Self-organizing map (SOM) gene lists for the first and third filters (two Excel worksheets, "HIV_SOM_Filt_1 $a$ " \& "HIV_SOM_Filt_3a")

Click here for file

[http://www.biomedcentral.com/content/supplementary/1742-

4690-2-20-S2.xls]

\section{Additional File 3}

K-means clustering gene lists (three Excel worksheets, "set1-5, " "set610," "set11-15")

Click here for file

[http://www.biomedcentral.com/content/supplementary/17424690-2-20-S3.xls]

\section{Additional File 4}

Gene lists filtered for all absent in pCep4 samples and at least 2 present calls in eTat samples (Excel worksheet, "2P"), 4 present calls in eTat samples (Excel worksheet, "4P"), and 8 present calls in eTat samples (Excel spreadsheet, " $8 P$ ")

Click here for file

[http://www.biomedcentral.com/content/supplementary/1742-

4690-2-20-S4.xls]

\section{Additional File 5}

Self-organizing map (SOM) for filter 1 (refer to Methods)

Click here for file

[http://www.biomedcentral.com/content/supplementary/1742-

4690-2-20-S5.jpeg]

\section{Additional File 6}

Self-organizing maр (SOM) for filter 2 (refer to Methods)

Click here for file

[http://www.biomedcentral.com/content/supplementary/17424690-2-20-S6.jpeg]

\section{Additional File 7}

K-means clustering (15 graphs and corresponding close-ups shown) Click here for file

[http://www.biomedcentral.com/content/supplementary/17424690-2-20-S7.ppt]

\section{Acknowledgements}

This work was supported by grants from the George Washington University REF funds to A. Vertes and F. Kashanchi, NIH grants Al44357, Al43894 and I 3969 to F.K, and grant IU24NS04357I-0I for the NINDS/NIMH Microarray Consortium. A.M. and W.S.L. contributed equally to this work. F.K. and D.A.S. share senior authorship on this work.

\section{References}

I. Baldwin CE, Sanders RW, Berkhout B: Inhibiting hiv-I entry with fusion inhibitors. Curr Med Chem 2003, 10:1633-1642. 
2. Kashanchi F, Agbottah ET, Pise-Masison CA, Mahieux R, Duvall J, Kumar A, Brady JN: Cell cycle-regulated transcription by the human immunodeficiency virus type I tat transactivator. J Virol 2000, 74:652-660.

3. Kundu M, Sharma S, De Luca A, Giordano A, Rappaport J, Khalili K, Amini S: Hiv-I tat elongates the gI phase and indirectly promotes hiv-I gene expression in cells of glial origin. J Biol Chem 1998, 273:8130-8136.

4. Ambrosino C, Palmieri C, Puca A, Trimboli F, Schiavone M, Olimpico F, Ruocco MR, di Leva F, Toriello M, Quinto I, Venuta S, Scala G: Physical and functional interaction of hiv-l tat with e2f-4, a transcriptional regulator of mammalian cell cycle. J Biol Chem 2002, 277:3|448-3|458

5. de la Fuente C, Santiago F, Deng L, Eadie C, Zilberman I, Kehn K, Maddukuri A, Baylor S, Wu K, Lee C, Pumfery A, Kashanchi F: Gene expression profile of hiv-I tat expressing cells: A close interplay between proliferative and differentiation signals. $B M C$ Biochem 2002, 3:14.

6. Clark E, Santiago F, Deng L, Chong S, de La Fuente C, Wang L, Fu P, Stein D, Denny T, Lanka V, Mozafari F, Okamoto T, Kashanchi F: Loss of $\mathrm{g}(\mathrm{I}) / \mathrm{s}$ checkpoint in human immunodeficiency virus type $\mathrm{I}$-infected cells is associated with a lack of cyclin-dependent kinase inhibitor p2 I/wafl. J Virol 2000, 74:5040-5052.

7. de la Fuente C, Wang L, Wang D, Deng L, Wu K, Li H, Stein LD, Denny T, Coffman F, Kehn K, Baylor S, Maddukuri A, Pumfery A, Kashanchi F: Paradoxical effects of a stress signal on pro- and anti-apoptotic machinery in htlv-I tax expressing cells. Mol Cell Biochem 2003, 245:99-I I 3.

8. Wang D, de la Fuente C, Deng L, Wang L, Zilberman I, Eadie C, Healey M, Stein D, Denny T, Harrison LE, Meijer L, Kashanchi F: Inhibition of human immunodeficiency virus type I transcription by chemical cyclin-dependent kinase inhibitors. J Virol 200I, 75:7266-7279

9. Corbeil J, Sheeter D, Genini D, Rought S, Leoni L, Du P, Ferguson M, Masys DR, Welsh JB, Fink JL, Sasik R, Huang D, Drenkow J, Richman $D D$, Gingeras $T$ : Temporal gene regulation during hiv-I infection of human cd4+ $t$ cells. Genome Res 200 I, I I: I 198-I 204.

10. van 't Wout AB, Lehrman GK, Mikheeva SA, O'Keeffe GC, Katze MG, Bumgarner RE, Geiss GK, Mullins Jl: Cellular gene expression upon human immunodeficiency virus type I infection of cd4(+)-t-cell lines. J Virol 2003, 77: I 392-1402.

II. Ensoli F, Fiorelli V, DeCristofaro M, Santini Muratori D, Novi A, Vannelli B, Thiele CJ, Luzi G, Aiuti F: Inflammatory cytokines and hivI-associated neurodegeneration: Oncostatin-m produced by mononuclear cells from hiv-I-infected individuals induces apoptosis of primary neurons. J Immunol 1999, 162:6268-6277.

12. Clegg CH, Rulffes JT, Wallace PM, Haugen HS: Regulation of an extrathymic t-cell development pathway by oncostatin $\mathbf{m}$. Nature 1996, 384:26I-263.

13. Falco GD, Neri LM, Falco MD, Bellan C, Yu Z, Luca AD, Leoncini L, Giordano A: Cdk9, a member of the cdc2-like family of kinases, binds to gp/30, the receptor of the il-6 family of cytokines. Oncogene 2002, $21: 7464-7470$

14. Alderson MR, Smith CA, Tough TW, Davis-Smith T, Armitage RJ, Falk B, Roux E, Baker E, Sutherland GR, Din WS: Molecular and biological characterization of human 4-Ibb and its ligand. Eur J Immunol 1994, 24:2219-2227.

15. DeBenedette MA, Chu NR, Pollok KE, Hurtado J, Wade WF, Kwon BS, Watts TH: Role of 4-I bb ligand in costimulation of $\mathbf{t}$ lymphocyte growth and its upregulation on $\mathrm{m} / 2$ b lymphomas by camp. J Exp Med 1995, I 81:985-992.

16. Shankar P, Schlom J, Hodge JW: Enhanced activation of rhesus $\mathbf{t}$ cells by vectors encoding a triad of costimulatory molecules (b7-I, icam-I, Ifa-3). Vaccine 200I, 20:744-755.

17. Kim JJ, Tsai A, Nottingham LK, Morrison L, Cunning DM, Oh J, Lee DJ, Dang K, Dentchev T, Chalian AA, Agadjanyan MG, Weiner DB: Intracellular adhesion molecule-I modulates beta-chemokines and directly costimulates t cells in vivo. J Clin Invest 1999, 103:869-877.

18. Bounou S, Leclerc JE, Tremblay MJ: Presence of host icam-I in laboratory and clinical strains of human immunodeficiency virus type I increases virus infectivity and cd4(+)-t-cell depletion in human lymphoid tissue, a major site of replication in vivo. J Virol 2002, 76:1004-1014.

19. Swingler S, Brichacek B, Jacque JM, Ulich C, Zhou J, Stevenson M: Hiv-I nef intersects the macrophage cd40I signalling path- way to promote resting-cell infection. Nature 2003, 424:213-219.

20. Bobardt MD, Saphire AC, Hung HC, Yu X, Van der Schueren B, Zhang Z, David G, Gallay PA: Syndecan captures, protects, and transmits hiv to t lymphocytes. Immunity 2003, I 8:27-39.

21. Cotter R, Williams C, Ryan L, Erichsen D, Lopez A, Peng H, Zheng J: Fractalkine (cx3clI) and brain inflammation: Implications for hiv-I-associated dementia. J Neurovirol 2002, 8:585-598.

22. Stumptner-Cuvelette $P$, Morchoisne S, Dugast M, Le Gall S, Raposo G, Schwartz O, Benaroch P: Hiv-I nef impairs mhc class ii antigen presentation and surface expression. Proc Natl Acad Sci U S A 200I, 98:12144-12149.

23. Cohen GB, Gandhi RT, Davis DM, Mandelboim O, Chen BK, Strominger JL, Baltimore D: The selective downregulation of class i major histocompatibility complex proteins by hiv-I protects hiv-infected cells from nk cells. Immunity 1999, 10:66|-67|.

24. Lozano JM, Gonzalez R, Kindelan JM, Rouas-Freiss N, Caballos R, Dausset J, Carosella ED, Pena J: Monocytes and t lymphocytes in hiv-I-positive patients express hla-g molecule. Aids 2002, 16:347-35I.

25. Gromadka R, Rytka J: The krr I gene encodes a protein required for 18 s rna synthesis and 40 s ribosomal subunit assembly in saccharomyces cerevisiae. Acta Biochim Pol 2000, 47:993-1005.

26. Sasaki T, Toh EA, Kikuchi Y: Yeast krr Ip physically and functionally interacts with a novel essential krilp, and both proteins are required for 40 s ribosome biogenesis in the nucleolus. Mol Cell Biol 2000, 20:797I-7979.

27. Chan HY, Brogna S, O'Kane CJ: Dribble, the drosophila krrlp homologue, is involved in rrna processing. Mol Biol Cell 200I, I 2:1409-1419.

28. Liu YZ, Latchman DS: The octamer-binding proteins oct-I and oct- 2 repress the hiv long terminal repeat promoter and its transactivation by tat. Biochem J 1997, 322(Pt I): I55-158.

29. Moriuchi M, Moriuchi $\mathrm{H}$ : Octamer transcription factors up-regulate the expression of ccr5, a coreceptor for hiv-I entry. J Biol Chem 200I, 276:8639-8642.

30. Chowdhury IH, Wang XF, Landau NR, Robb ML, Polonis VR, Birx DL, $\mathrm{Kim} \mathrm{JH}$ : Hiv-I vpr activates cell cycle inhibitor $\mathbf{p 2}$ I/wafl/cip I: a potential mechanism of $\mathbf{g} 2 / \mathbf{m}$ cell cycle arrest. Virology 2003 , 305:37I-377.

31. Yang R, Muller C, Huynh V, Fung YK, Yee AS, Koeffler HP: Functions of cyclin al in the cell cycle and its interactions with transcription factor e2f-I and the rb family of proteins. Mol Cell Biol 1999, 19:2400-2407.

32. Prasad MV, Shanmugam G: Retinoblastoma gene inhibits transactivation of hiv-Itr linked gene expression upon co-transfection in he la cells. Biochem Mol Biol lnt 1993, 29:57-62.

33. Hall M, Bates S, Peters G: Evidence for different modes of action of cyclin-dependent kinase inhibitors: p 15 and p 16 bind to kinases, p2I and p27 bind to cyclins. Oncogene 1995, II:I58I-I588.

34. Clarke B, Chetty R: Cell cycle aberrations in the pathogenesis of squamous cell carcinoma of the uterine cervix. Gynecol Oncol 200I, 82:238-246.

35. Sun J, Barbeau B, Sato S, Tremblay MI: Neuraminidase from a bacterial source enhances both hiv-I-mediated syncytium formation and the virus binding/entry process. Virology 200I, 284:26-36.

36. Hart ML, Saifuddin M, Spear GT: Glycosylation inhibitors and neuraminidase enhance human immunodeficiency virus type I binding and neutralization by mannose-binding lectin. J Gen Virol 2003, 84:353-360.

37. Morimoto K, Shimizu T, Furukawa K, Morio H, Kurosawa H, Shirasawa $T$ : Transgenic expression of the ext 2 gene in developing chondrocytes enhances the synthesis of heparan sulfate and bone formation in mice. Biochem Biophys Res Commun 2002, 292:999-1009.

38. Werth N, Schuette CG, Wilkening G, Lemm T, Sandhoff K: Degradation of membrane-bound ganglioside gm2 by beta -hexosaminidase a. stimulation by $\mathrm{gm} 2$ activator protein and lysosomal lipids. J Biol Chem 200I, 276: I 2685-I2690.

39. Wu X, Okada N, Momota H, Irie RF, Okada H: Complementmediated anti-hiv- $I$ effect induced by human igm monoclonal antibody against ganglioside gm2. J Immunol 1999, 162:533-539. 
40. Okada N, Wu X, Mizokami M, Irie RF, Okada H: Human igm monoclonal antibody to ganglioside gm2 and complement suppress virus propagation in ex vivo cultures of lymphocytes from hiv-I infected patients. Microbiol Immunol I 999, 43:723-727.

41. de la Fuente C, Maddukuri A, Kehn K, Baylor SY, Deng L, Pumfery A, Kashanchi F: Pharmacological cyclin-dependent kinase inhibitors as hiv-I antiviral therpaeutics. Current HIV Research 2003, I:I3I-I52.

42. Schang LM, Bantly A, Knockaert M, Shaheen F, Meijer L, Malim MH, Gray NS, Schaffer PA: Pharmacological cyclin-dependent kinase inhibitors inhibit replication of wild-type and drugresistant strains of herpes simplex virus and human immunodeficiency virus type I by targeting cellular, not viral, proteins. J Virol 2002, 76:7874-7882.

43. Ching YP, Chun AC, Chin KT, Zhang ZQ, Jeang KT, Jin DY: Specific TATAA and bZIP requirements suggest that HTLV-I Tax has transcriptional activity subsequent to the assembly of an initiation complex. Retrovirology 2004, I: I8.

44. De La Fuente $C$, Kashanchi $F$ : The expanding role of Tax in transcription. Retrovirology 2004, I: 19.

45. Liu YZ, Lania L, Latchman DS: Functional interaction between the hiv-I tat transactivator and the inhibitory domain of the oct-2 cellular transcription factor. Aids 1996, 10:1323-1329.

46. Stoiber H, Pinter C, Siccardi AG, Clivio A, Dierich MP: Efficient destruction of human immunodeficiency virus in human serum by inhibiting the protective action of complement factor $h$ and decay accelerating factor (daf, cd55). J Exp Med 1996, 183:307-310.

47. Sieg SF, Harding CV, Lederman MM: Hiv-I infection impairs cell cycle progression of cd4(+) t cells without affecting early activation responses. J Clin Invest 200I, 108:757-764.

48. Matsuo $M$, Sakurai $H$, Saiki I: $\mathbf{Z d}$ a selective epidermal growth factor receptor tyrosine kinase inhibitor, shows antimetastatic activity using a hepatocellular carcinoma model. Mol Cancer Ther 1839, 2:557-56I.

49. Suga $S$, Tsurudome $M$, Ito $M$, Ohgimoto $S$, Tabata $N$, Nishio $M$, Kawano M, Komada H, Sakurai M, Ito Y: Human immunodeficiency virus type-I envelope glycoprotein gp I20 induces expression of fusion regulatory protein (frp)- I/cd98 on cd4+ $t$ cells: A possible regulatory mechanism of hiv-induced syncytium formation. Med Microbiol Immunol (Berl) 1997, 185:237-243.

50. Krishnan V, Zeichner SL: Host cell gene expression during human immunodeficiency virus type I latency and reactivation and effects of targeting genes tha are differentially expressed in viral latency. J Virol 2004, 78:9458-73.

5I. Maniatis T, Reed R: An extensive network of coupling among gene expression machines. Nature 2002, 416:499-506. Review

52. Furia B, Deng L, Wu K, Baylor S, Kehn K, Li H, Donnelly R, Coleman T, Kashanchi F: Enhancement of nuclear factor-kappa B acetylation by coactivator $\mathrm{p} 300$ and hiv-I tat proteins. J Biol Chem 2002, 277:4973-80.

53. Agbottah E, de La Fuente C, Nekhai S, Barnett A, Gianella-Borradori A, Pumfery A, Kashanchi F: Antiviral activity of cyc202 in hiv-Iinfected cells. J Biol Chem 2005, 280:3029-42.

54. Kohonen T: Self-organizing maps. 3rd edition. Heidelberg: Springer-Verlag; 2001.

55. Hautaniemi S, Yli-Harja O, Astola J, Kauraniemi P, Kallioniemi A, Wolf $M$, Ruiz J, Mousses S, Kallioniemi O: Analysis and visualization of gene expression microarray data in human cancer using selforganizing maps. Machine Learning 2003, 52:45-66.

56. Vesanto J, Himberg J, Alhoniemi E, Parhankangas J: Som toolbox for matlab 5. In Book Som toolbox for matlab 5 (Editor ed) 5th edition. Helsinki University of Technology; 2000:A57.
Publish with Bio Med Central and every scientist can read your work free of charge

"BioMed Central will be the most significant development for disseminating the results of biomedical research in our lifetime. "

Sir Paul Nurse, Cancer Research UK

Your research papers will be:

- available free of charge to the entire biomedical community

- peer reviewed and published immediately upon acceptance

- cited in PubMed and archived on PubMed Central

- yours - you keep the copyright

Submit your manuscript here:

http://www.biomedcentral.com/info/publishing_adv.asp
BioMedcentral 